\title{
Dinâmica da taxa de câmbio no Brasil de 2004 a 2012: efeitos da crise econômico- financeira internacional de 2008
}

\author{
Jayane Pereira de Oliveira* \\ Roberto Arruda de Souza Lima**
}

\begin{abstract}
Resumo: Este trabalho objetiva investigar se há evidências de alteração do regime cambial brasileiro no pós-crise internacional de 2008, além de captar lições acerca da eficácia dos instrumentos de intervenção recentemente aplicados sobre o mercado de moedas. Foi utilizado o modelo Markov Switching aplicado à equação estrutural de curto prazo para taxa de câmbio. Os resultados indicam não haver evidências representativas que conduzam à interpretação de alteração no regime de política cambial. Verificou-se também que as intervenções das autoridades monetárias e fiscais não obtiveram eficácia em gerir ou direcionar a variação ou nível da taxa de câmbio.
\end{abstract}

Palavras-Chave: Markov switching. IOF. Intervenções cambiais. Câmbio fundamental.

\section{Brazilian foreign exchange rate dynamics from 2004 to 2012: effects of the international economic and financial crisis of 2008}

\begin{abstract}
This study seeks to investigate whether there is evidence of changes in the Brazilian foreign exchange rate regime after the 2008's international crisis. Furthermore, it get lessons on the effectiveness of the intervention measures recently applied on the currency market. This investigation uses Markov switching model applied to the structural short-term exchange rate equation. The results indicate there is no significant evidence of changes in the dynamic of exchange rate in the post-crisis that explains changes in the foreign exchange rate regime adopted by Brazil. The intervention of monetary authorities was not efficient in managing or guiding changes in the exchange rate level.
\end{abstract}

Keywords: Markov switching. IOF. Foreign exchange rate interventions. Foreign exchange rate fundamentals.

Classificação JEL: E42; E52; E32.

\section{Introdução}

Este trabalho tem por objetivo verificar se há evidências de mudança no regime cambial adotado pelo Brasil no pós-crise 2008. Algumas atipicidades na gestão das políticas monetária, cambial e fiscal pelas respectivas autoridades e a própria trajetória seguida pela taxa de câmbio conduzem a esse questionamento. Outros motivadores são o contexto histórico de escolha e implementação dos regimes de taxa de câmbio, a ausência de um objetivo claro e bem definido

\footnotetext{
*Mestre em Economia Aplicada, Escola Superior de Agricultura "Luiz de Queiroz", Universidade de São Paulo. E-mail: jayane_x@yahoo.com.br

** Professor na Escola Superior de Agricultura "Luiz de Queiroz", Universidade de São Paulo. E-mail: raslima@usp.br
} 
de política cambial e o descolamento entre a taxa de câmbio brasileira em comparativo com outros países que possuem estrutura econômica semelhante.

Observando a gestão realizada sobre a taxa de câmbio nos anos recentes, não é possível identificar uma definição clara de objetivos, metas e instrumentos por parte das autoridades monetárias. No Comunicado 6.565, que dispõe sobre o regime de câmbio flutuante no Brasil, o Banco Central (BCB) afirma que “[...] deixará que o mercado interbancário (segmentos livre e flutuante) defina a taxa de câmbio" (BANCO CENTRAL DO BRASIL, 2012, p. 1) e que poderá intervir nos mercados "[...] ocasionalmente e de forma limitada com objetivo de conter movimentos desordenados das taxas de câmbio" (BANCO CENTRAL DO BRASIL, 2012, p. 1). Poder-se-ia afirmar que o câmbio flutuar per si seria o objetivo de política cambial. No entanto, a intervenção no mercado de moedas é desempenhada ativamente pelo BCB durante todo o período de flutuação e com intensificação após a crise econômico-financeira internacional, o que se mostra incoerente com esse argumento. Ademais, se o objetivo da intervenção é conter movimentos desordenados da taxa de câmbio, pressupõe-se que haja uma ordem, um caminho ideal de trajetória dessa variável que a autoridade monetária perseguiria. Entretanto, ao menos oficialmente, essa meta não foi divulgada e se isso ocorresse, estaria inconsistente com a definição de regime de flutuação.

Consequente do gerenciamento da política cambial implementado, está o regime cambial a ser identificado em um país. Conforme Frenkel e Rapetti (2010), um regime de taxa de câmbio é definido pelas regras seguidas pelo Banco Central em relação ao grau de intervenção no mercado de moeda estrangeira, seria, portanto, o grau de compromisso oficial em determinar a taxa de câmbio nominal. Pautado nessa definição, esse autor afirma que todas as grandes economias latino-americanas - entre elas o Brasil, o Chile e a Colômbia - que se arrogam oficialmente políticas monetárias de metas de inflação e regime de flutuação estão, de fato, sob o regime de flutuação administrada, mas apenas a Argentina o assume oficialmente.

O regime cambial no Brasil de jure classificado como de flutuação, de facto, em sua origem já previa a administração da taxa de câmbio, como em todas as demais economias latinoamericanas que tem assumido a sua implementação, desde a década de 1990. Como afirmam Calvo e Reinhart (2002), é amplamente aceito que a flutuação pura é um artefato de livros-texto de Economia. Anterior ao regime de câmbio flutuante, a fim de dar sustentabilidade às âncoras monetária e cambial que convalidavam a estabilização da inflação, a taxa de câmbio foi estabelecida em regime de bandas. Segundo Dornbush e Fischer (1986), em países com passado inflacionário, o comportamento da taxa de câmbio nominal tende a afetar as expectativas de 
inflação e os mecanismos de fixação de preços dos bens não comercializáveis e dos salários, o que torna a taxa de câmbio nominal variável-chave na determinação da inflação. Convergindo para esse argumento, Frenkel e Rapetti (2010) afirmam que nas circunstâncias em que a estabilização da inflação se torna uma emergência, a escolha do regime cambial passa a ser quase que exclusivamente conduzida pelo objetivo de estabilização de preços. O mesmo é observado em economias que possuem estrutura econômica semelhante a do Brasil, de crescimento com poupança externa positiva e balanço de pagamento pautado em commodities, que similarmente, impuseram a administração da paridade do valor da moeda doméstica com o dólar americano, como a Argentina, México, Chile e Colômbia. Os dois primeiros países com foco na paridade nominal, tal como o Brasil, e os demais, cujos processos inflacionários foram menos severos, com ênfase na manutenção de uma taxa de câmbio real relativamente competitiva (FRENKEL; RAPETTI, 2010).

O regime de bandas cambiais manteve-se até a perda da sustentabilidade ao fim da década de 1990, provocada pela crise do México (1994), crise da Ásia (1997) e crise da Rússia (1998) - crise econômico-financeira internacional. Com a vultosa fuga de capitas e ataques especulativos, o compromisso de manutenção do câmbio nos limites de variação não pôde ser mantido, haja vista o insuficiente aporte de reservas de dólar, nesse sentido, as autoridades permitiram a flutuação. O mesmo ocorreu de forma generalizada nas economias emergentes latino-americanas, que sucessivamente, declararam a livre flutuação. Como conclui Silveira (2003), boa parte dos países que optaram pela livre flutuação cambial, fizeram-no após brusca redução de reservas devido à defesa da paridade fixa em regime anterior. Tendo em vista esse processo, pode-se afirmar que a opção pelo câmbio flutuante não foi um livre planejamento de política econômica, mas uma reação política para alcançar a estabilidade econômica em conjuntura de crise. Em consonância com essa ideia, o BCB, no boletim de Análise do Mercado de Câmbio, referindo-se ao início do ano de 1999, cita que

[...] a confluência de fatos negativos, tanto de ordem econômica quanto política, passaram a instigar o nervosismo e insegurança do mercado, fomentando clima negativo sinalizador da iminência de mudanças na política cambial então vigente (BANCO CENTRAL DO BRASIL, 2012, p. 1)

Teriam sido essas "confluências de fatos negativos" externa e internamente à Economia brasileira os determinantes para a extinção do regime de bandas cambiais pelo BCB. Observase que, como preço internacional que conecta uma Economia aberta ao resto do mundo, a taxa de câmbio, assim como os regimes cambiais, está sob as ingerências da capacidade do país em suportar a conjuntura externa e com ela se relacionar de maneira sustentável. Sustentável aqui 
se referindo à possibilidade de se relacionar com o mundo sem romper com a ordem econômica internamente estabelecida. Nessa mesma ideia, Frenkel e Rapetti (2010) afirmam que o processo de escolha do regime cambial na América Latina tem sido influenciado em grande medida pelo grau de liberdade ou urgência, historicamente específicos, com que os países têm conduzido os objetivos políticos.

Essa reflexão trazida para a conjuntura atual do regime cambial brasileiro é de grande aderência. Historicamente, o Brasil, como as demais economias latino-americanas, tem estabelecido o regime cambial como uma política de reação à conjuntura de crise externa que internamente se reflete em instabilidade das variáveis macroeconômicas. Na atual conjuntura de crise financeira internacional originada nas hipotecas subprime, invariavelmente as autoridades monetárias e fiscais têm executado medidas de política, sobre o mercado cambial, monetário e o mercado financeiro e de capitais, não tradicionais e não esterilizadas - com clara intenção de direcionar a trajetória da taxa de câmbio. Por exemplo, a taxação do $\mathrm{IOF}^{1}$ sobre o mercado de derivativos de câmbio e especialmente sobre ampliação da posição vendida, em julho e dezembro de 2011, bem como sobre o capital estrangeiro aplicado em renda fixa e variável em outubro de 2009 e outubro de 2010 e a elevação do compulsório sobre as posições vendidas assumidas pelos bancos em janeiro e julho de 2011, entre outras, que foram registradas pela última vez durante o regime de bandas. Conforme Almeida et al. (2000), no ano de 1995, ano de implementação do regime de bandas, para manter a taxa de câmbio dentro dos limites fixados foram editadas diversas medidas como a redução das alíquotas do IOF sobre o ingresso de recursos externos como também foi reduzido o valor da posição comprada de câmbio que poderia permanecer com os bancos, cujo recurso excedente deveria ser compulsoriamente depositado no BCB.

Ademais, além das medidas de gestão da política cambial, monetária e de controle de capitais, observada a trajetória do real comparada a das economias com estrutura econômica semelhante, essencialmente baseadas na exportação de commodities, é observado um distanciamento da moeda brasileira. Dada a principal fonte de exportação dessas economias, em não havendo modificações estruturais no Brasil, o que parece ser o caso, o principal fundamento determinante das variações no valor da moeda, é o preço internacional das commodities, que influencia todas as economias na mesma direção. Parece ocorrer, portanto,

\footnotetext{
${ }^{1}$ IOF: Imposto sobre Operações de Crédito, Câmbio e Seguros ou relativas a Títulos ou Valores Mobiliários.
} 
que o movimento das taxas de câmbio tem sido direcionado, por fatores outros que não os fundamentos.

Em outro ponto, uma discussão proeminente entre os economistas brasileiros, assentase sobre o direcionamento da política econômica do país para uma "nova matriz macroeconômica”. Márcio Holland, Secretário de Política Econômica, concedeu entrevista ao jornal Valor Econômico em que descreve essa matriz como sendo um combinado de juro baixo, taxa de câmbio competitiva (descrita como desvalorizada) e uma consolidação fiscal (HOLLAND, 2013). Ele também afirma que essa matriz não substitui o tripé meta de inflação, fiscal e câmbio flutuante. Entretanto, a teoria econômica não comporta câmbio flutuante e meta de câmbio em uma mesma classificação.

Considerando toda essa perspectiva, este trabalho pretende objetivamente analisar, descrever e realizar um teste no modelo de regime cambial adotado pelo Brasil na busca por identificar evidências empíricas de ocorrência de uma transição de regime cambial. Essa caracterização faz-se importante frente ao contexto recente da política econômica adotada pelo País. O gerenciamento da Economia é pautado no tripé de equilíbrio fiscal, de inflação e, como descrito anteriormente, no caráter administrado, mas não controlado, das taxas de câmbio, o que é plenamente comportado pelo mercado. Entretanto, um controle excessivo sobre os movimentos cambiais, descaracteriza a qualificação do regime cambial, colocando-o em uma posição de regime de bandas. Isso ocasiona importantes alterações teóricas: para o regime de metas de inflação, o instrumento primário oficial de combate à alta de preços é a taxa de juros Selic, como consta em Banco Central do Brasil (2013) e Bogdanski et al. (2000), e, desde a sua adoção, o câmbio tem sido utilizado como ferramenta auxiliar para o equilíbrio econômico, entretanto sem uma meta que o defina. Dessa forma, os movimentos das taxas de juros são comportados nas expectativas dos agentes. Contudo, atribuir além dessa âncora monetária, um âncora cambial extrapola o campo teórico e torna-se mais um componente, cujo comportamento é desconhecido, a modelar as expectativas dos agentes. Isso pode gerar crises de confiança, como nos anos de 2001 e 2002, de forma que o direcionamento de política dado pelo BCB por meio da Selic e o comportamento dos agentes não confluam, em outras palavras, a política monetária pode tornar-se menos eficaz.

Sumariamente, descrevem-se, portanto, três motivadores principais para esse trabalho:

1. O contexto histórico de escolha e implementação dos regimes de taxa de câmbio; geralmente em ambiente de crise e por impossibilidade de manutenção do regime em curso. 
2. A dinâmica da taxa de câmbio vis-à-vis outras commodity currency: descolamento da trajetória.

3. Intervenções sobre o mercado de moeda pós-crise de 2008: atipicidades na gestão das políticas monetária, cambial e fiscal e a ausência de um objetivo claro e bem definido de política cambial.

Essas três proposições levam aos seguintes questionamentos: a dinâmica da taxa de câmbio é significativamente diferente entre os períodos anterior e pós-crise que justifique se falar em um novo regime de câmbio ou especificamente em um regime de bandas? Se sim, quanto aos fatores que determinaram essa mudança, seria por interferência política ou mudança nos fundamentos?

A fim de esclarecer essas questões são testadas as hipóteses: 1) as políticas de intervenção no mercado de moeda são eficazes na gestão da dinâmica do câmbio; 2) no póscrise 2008 houve redução no poder explicativo dos fundamentos de câmbio; 3) há evidências de ocorrência de mudança de regime de câmbio no pós-crise 2008.

\subsection{Correlação entre taxas de câmbio: commodities currencies}

Em economias pequenas com baixa intervenção no mercado de câmbio, e cuja exportação tem por principais componentes as commodities, a volatilidade desses produtos tende a ter grande influência na flutuação dos termos de troca e, por sua vez, nos movimentos da taxa de câmbio. Nesse caso, se o valor da moeda se move em reflexo aos preços internacionais das commodities, essa moeda é denominada commodity currency (CLEMENTS; FRY, 2008; CHEN; ROGOFF, 2003).

Chen e Rogoff (2003) aplicaram um teste de cointegração entre as moedas do Canadá, Nova Zelândia e Austrália e o índice de commodities internacional. Os autores concluíram que as taxas de câmbio desses países se caracterizam como commodity currencies. Sanidas (2013) utilizou essas mesmas moedas e ainda a coroa norueguesa, a fim de avaliar se a cotação da moeda é determinada como um conjunto de ciclos harmônicos que, por sua vez, seria baseado nos ciclos de preços ou de produção de commodities. Tal como Chen e Rogoff (2003), Sanidas (2013) conseguiu evidências suficientes para determinar essas moedas como commodity currencies e vai além, enquadrando também nessa classificação o real brasileiro, o peso chileno, o rand sul africano, o dólar canadense, o dólar australiano e o dólar neozelandês. Na mesma 
vertente, Clements e Fry (2008) citam como commodity currencies a Austrália, Nova Zelândia, África do Sul e Canadá.

Dada a característica de commodity currency das moedas supracitadas, por definição, a dinâmica de suas trajetórias é altamente influenciada pela variação nos preços dos produtos 'comoditizados', e, portanto, consequente de determinante comum, ocorre relação muito próxima de variação das cotações, o que se verifica na figura 1. Dessa perspectiva teórica decorre a segunda motivação para este trabalho: nos anos recentes, há um descolamento entre o movimento da taxa de câmbio brasileira e das demais commodity currencies citadas na literatura - com exceção apenas do rand sul africano que acompanha o real (figura 1). Acerca disso, Kohlscheen (2010) sugere que países que são commodity currency podem não apresentar essa característica em dado período porque não se permitiu que a taxa de câmbio flutuasse como tal. Um possível provocativo seria o gerenciamento da cotação da moeda e a rigidez de preços.

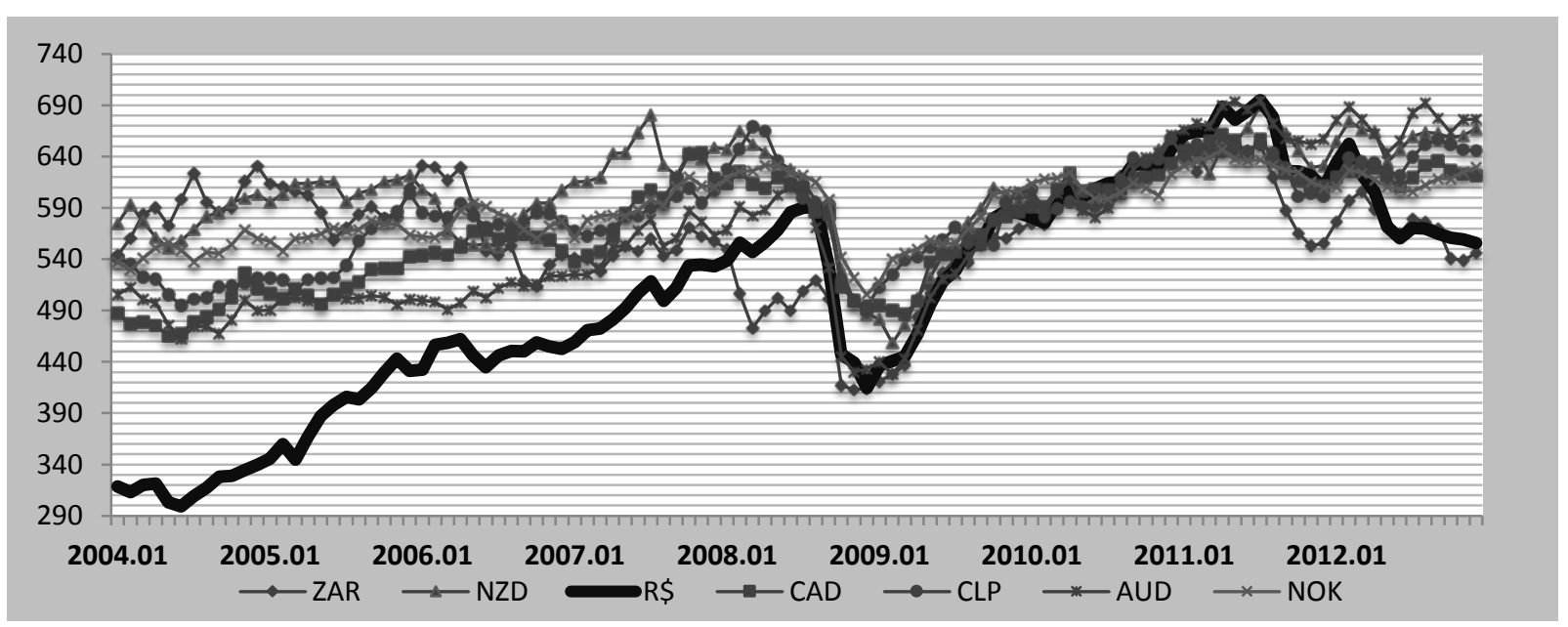

Figura 1: Descolamento entre o real e demais moedas commodity currencies Fonte: Elaboração própria

Notas: 1 Índice internacional de commodities em moeda doméstica dos países commodity currencies.

2 R\$: real; ZAR: rand sul africano; NZD: dólar neozelandês; CAD: dólar canadense; CLP: peso chileno; AUD: dólar australiano; NOK: coroa norueguesa.

3 Fonte de dados: real effective exchange rate (Bank for International Settlements), Índice de preços de commodities (Commodity Research Bureau).

\subsection{Gestão da política cambial pós-crise 2008}

O terceiro motivador para este trabalho é resumido na tabela 1. Tradicionalmente as políticas de intervenção no mercado de câmbio utilizadas pelo BCB são as operações no mercado à vista e as taxas de juros. Entretanto, como se pode observar na tabela 1 , com a crise internacional, houve inovação de políticas de gerenciamento do câmbio, principalmente com o uso de controle do fluxo de capitais via tributação. 
Tabela 1: Gestão Cambial: medidas monetárias e fiscais - taxa em \%

\begin{tabular}{|c|c|c|}
\hline \multicolumn{3}{|c|}{ IOF } \\
\hline Publicação & Sobre empréstimos externos & Regulamento \\
\hline $03 / 01 / 2008$ & até 90 dias: $5,38 \%$ & Decreto 6.339 \\
\hline $29 / 03 / 2011$ & 360 dias: $6 \%$ & Decreto 7.456 \\
\hline 04/04/2011 & sujeito a câmbio simultâneo; pagamento: $0,38 \%$; nova captação: $6 \%$ & \\
\hline 06/04/2011 & $\begin{array}{l}\text { até } 720 \text { dias ( } 2 \text { anos): } 6 \% \text {; inclui: emissão de títulos, repactuação e } \\
\text { assunção de dívidas e empréstimos intercompanhias do mesmo prazo }\end{array}$ & Decreto 7.457 \\
\hline 29/02/2012 & até 3 anos: $6 \%$ & Decreto 7.683 \\
\hline 09/03/2012 & até 1.800 dias ( 5 anos): $6 \%$ & Decreto 7.698 \\
\hline $13 / 06 / 2012$ & até 720 dias ( 2 anos): $6 \%$ & Decreto 7.751 \\
\hline $05 / 12 / 2012$ & 360 dias: $6 \%$ & Decreto 7.853 \\
\hline \multicolumn{3}{|c|}{ Sobre investimentos estrangeiros } \\
\hline $12 / 03 / 2008$ & no mercado financeiro e de capitais: $1,5 \%$ & Decreto 6.391 \\
\hline $19 / 10 / 2009$ & no mercado financeiro e de capitais: $2 \%$ & Decreto 6.983 \\
\hline $04 / 10 / 2010$ & em fundos de renda fixa e títulos do Tesouro: $4 \%$ & Decreto 7.323 \\
\hline 07/10/2010 & $\begin{array}{l}\text { migração de aplicações em renda variável para aplicações em renda fixa } \\
\text { está sujeita câmbio simultâneo }\end{array}$ & Resolução 3.912 \\
\hline $18 / 10 / 2010$ & em renda fixa: $6 \%$ & Decreto 7.330 \\
\hline $01 / 12 / 2011$ & $\begin{array}{l}\text { de portfólio em renda fixa e títulos privados de longo prazo (acima } 4 \\
\text { anos): } 0 \%\end{array}$ & Decreto 7.632 \\
\hline \multicolumn{3}{|c|}{ Sobre o mercado de derivativos } \\
\hline $18 / 10 / 2010$ & sobre margem de garantia : $6 \%$ & Decreto 7.330 \\
\hline 27/07/2011 & $\begin{array}{l}\text { sobre posição vendida em mercados de derivativos cambiais (superior a } \\
\text { US\$ } 10 \text { milhões): } 1 \%\end{array}$ & Decreto 7.536 \\
\hline $08 / 12 / 2011$ & sobre operações: $1 \%-25 \%$ & $\begin{array}{l}\text { Lei 12.543/2011(MP } \\
539 / 2011 \mathrm{de} \\
28 / 07 / 2011)\end{array}$ \\
\hline $15 / 03 / 2012$ & $\begin{array}{l}\text { sobre posição vendida em derivativos para exportadores realizando } \\
\text { hedge cambial: } 0 \% \text { (observado limite de } 1,2 \text { vezes o valor exportado no } \\
\text { ano anterior) }\end{array}$ & Decreto 7.699 \\
\hline \multicolumn{3}{|c|}{$\begin{array}{l}\text { RECOLHIMENTO COMPULSÓRIO } \\
\end{array}$} \\
\hline \multicolumn{3}{|c|}{ Sobre instituições financeiras } \\
\hline $06 / 01 / 2011$ & $\begin{array}{l}\text { Compulsório de } 60 \% \text { do valor das posições vendidas em câmbio } \\
\text { exceder o menor dos seguintes valores: US } \$ 3 \text { bilhões ou o patrimônio } \\
\text { de referência (Nível I) }\end{array}$ & Circular 3.520 \\
\hline 08/07/2011 & Compulsório de $60 \%$ sobre posição vendida de até US\$ 1 bilhão & Circular 3.548 \\
\hline $18 / 12 / 2012$ & Compulsório de $60 \%$ sobre posição vendida de até US\$ 3 bilhões & Circular 3.619 \\
\hline \multicolumn{3}{|c|}{ RESTRIÇÃO DE CAPITAL } \\
\hline $01 / 03 / 2012$ & $\begin{array}{l}\text { Restringe a antecipação de pagamento aos exportadores a captações } \\
\text { com prazo máximo de } 360 \text { dias e financiadas exclusivamente pelo } \\
\text { importador direto }\end{array}$ & Circular 3.580 \\
\hline 28/06/2012 & $\begin{array}{l}\text { Pagamento antecipado a exportadores poderá novamente ser financiado } \\
\text { por instituições financeiras. }\end{array}$ & Circular 3.604 \\
\hline $04 / 12 / 2012$ & $\begin{array}{l}\text { Pagamento antecipado a exportadores volta a ser permitido para } \\
\text { captações de mais de } 360 \text { dias, com limite superior de } 5 \text { anos. }\end{array}$ & Circular 3.617 \\
\hline
\end{tabular}


O primeiro instrumento de política abordado na Tabela 1 é a alíquota do IOF. Esse imposto não é novo, foi instituído pela Lei n ${ }^{\circ}$ 5.143, de 20 de outubro de 1966, entretanto foi regulamentado para incidir sobre operações cambiais anos depois, na Lei $n^{\circ} 8.894$ de 21 de junho de 1994. O fato gerador do IOF/câmbio é, conforme o Código Tributário Nacional, a “[...] entrega de moeda nacional ou estrangeira, ou de documento que a represente, ou sua colocação à disposição do interessado, em montante equivalente à moeda estrangeira ou nacional entregue ou posta à disposição" (BRASIL, 2013, Art. 63) e previa alíquota de 25\%, entretanto, para a maioria das operações incidia alíquota de $2 \%$ ou zerada.

A partir de janeiro de 2008, como descrito na tabela 1, ocorreram as principais modificações nas alíquotas e incidência do IOF/câmbio. Do IOF sobre operações de câmbio destinadas a empréstimos externos verifica-se, inicialmente, aumento de alíquota e posterior elevação do prazo de aplicação sobre o qual tem incidência que se seguiu até o fim de 2012. Uma clara tentativa das autoridades de desestimular a entrada de capitais de curto prazo, considerados especulativos. Também sobre operações de câmbio destinadas a investimento estrangeiro no mercado financeiro e de capitais (renda fixa e variável) as alíquotas aumentaram gradativamente sob idêntica intenção. Já sobre posições líquidas vendida em derivativos de câmbio houve a implementação de IOF no fim de 2010. Teoricamente essa tributação poderia conter pressões apreciativas sobre a taxa de câmbio que se formassem no mercado futuro, isso pressupondo que o preço do dólar se forma no mercado futuro e é transmitido para o mercado de dólar pronto.

Além do IOF/câmbio, outras medidas instituídas que podem afetar a cotação da moeda foram o recolhimento compulsório de $60 \%$ sobre posição vendida das instituições financeiras (essencialmente bancos) e a restrição a antecipação de pagamento aos exportadores, ambas pressões por valorização do real. Da observação dessas medidas surgem discussões recentes entre os economistas de que o país teria implicitamente mudado para um regime de bandas cambiais.

\subsection{Modelo de mudança markoviana de regime (Markov Switching)}

Para avaliar a possibilidade de ocorrência de um processo de mudança de regime cambial no período pós-crise de 2008 , a série da taxa de câmbio foi modelada conforme sugere a literatura, utilizando o modelo de mudança de regime markoviana. Nessa modelagem são incorporados os fundamentos do câmbio e as intervenções sobre sua dinâmica. Nesta seção, 
portanto, deseja-se responder a questão: por que utilizar o modelo de mudança de regime para modelar a dinâmica da taxa de câmbio?

Conforme Sarno et al. (2004), uma vasta literatura tem fornecido evidências de que as mudanças na distribuição condicional da taxa de câmbio nominal são bem descritas com uma mistura de normais e que um modelo de mudança de regime markoviana apresenta bom ajuste ao comportamento dessa variável. Há certa dificuldade entre os pesquisadores em produzir modelos que se ajustem bem e produzam boas previsões para a taxa de câmbio nominal. Existem tanto modelos que se baseiam em fundamentos macro ou microeconômicos, como aqueles puramente estatísticos. Entre esses, o modelo de passeio aleatório é muito aplicado, mas sua qualidade é colocada em dúvida por teóricos que testaram o modelo de mudança de regime markoviana. De fato, a literatura acadêmica ainda não chegou a um consenso se modelos com fundamentos, ou puramente estatísticos ou ainda estado-dependentes são capazes de superar os resultados do passeio aleatório sem drift quando prevê a taxa de câmbio fora da amostra (NIKOLSKO-RZHEVSKYY; PRODAN, 2012). Entretanto, tem surgido uma grande quantidade de estudos empíricos que demonstram a superioridade do modelo de mudança de regime em se ajustar aos dados e na estimação do comportamento da taxa de câmbio. Esse modelo seria bastante consistente com a série temporal gerada por regimes cambiais de flutuação suja (LEE; CHEN, 2006; ENGEL, 1994).

Trabalho seminal acerca do uso do modelo de mudança de regime markoviana em séries de taxa de câmbio foi apresentado por Engel e Hamilton (1990). Esses autores demostraram que o Markov switching apresenta melhores resultados que estimações que consideram a série de câmbio um passeio aleatório. Também Bergman e Hansson (2005) e Bollen et al. (2000) chegaram a resultados semelhantes, aqueles sugerindo que a taxa de câmbio real possa ser modelada com um processo autorregressivo de primeira ordem sujeito a mudança de regime, com dois estados; e esses que compararam os modelos Garch e de mudança de regime, tendo concluído a superioridade desse último.

Também outros autores adeptos dessa técnica de modelagem desenvolveram trabalhos com a finalidade de testar a qualidade de ajuste e previsão do modelo de mudança de regime. Yuan (2011) apresenta um modelo de previsão aplicado à taxa de câmbio que combina o modelo de mudança de Markov com técnicas de suavização. Tal como Lee e Chen (2006) esse autor demonstra que esse modelo apresenta melhores resultados em termos de erro quadrado médio da previsão que o passeio aleatório. Ele afirma que o ponto central do modelo é explorar o fato da série de taxa de câmbio seguir uma tendência fortemente persistente e, por sua vez, 
identifica-la permite prescindir do passeio aleatório. Também Nikolsko-Rzhevskyy e Prodan (2012) convergem para os resultados encontrados por Lee e Chen (2006). Nikolsko-Rzhevskyy e Prodan (2012) trouxeram duas importantes contribuições: 1) avaliaram os modelos macroeconômicos recentes de previsão de taxa de câmbio e encontram que o sucesso desses modelos deve-se, em parte, ao termo constante (drift) conjunto aos fundamentos econômicos e 2) modelaram o drift usando o modelo de mudança de regime markoviana e encontraram fortes evidências de que esse modelo apresenta melhores resultados que os modelos de passeio aleatório.

A combinação da modelagem estado-dependente com teorias que definem equações estruturais para a taxa de câmbio também contribuiu para melhorar os ajustes dos modelos. Lee e Chen (2006) propõem um modelo de determinação da taxa de câmbio baseado em expectativas racionais e aplicado a regimes de flutuação suja. Esses autores argumentam que o modelo de mudança de regime é o mais adequado para se aplicar aos regimes de câmbio devido à flutuação suja, que implica intervenções que desviam a taxa de câmbio dos fundamentos. Seja nos países que adotam a flutuação administrada ou nos que se declaram flutuantes, mas que gerenciam o valor da taxa de câmbio, os movimentos dessa variável são resposta aos movimentos das forças de mercado, como também refletem as intervenções do Banco Central, no mercado cambial, com a intenção de prevenir movimentos indesejados da taxa de câmbio ou para alcançar alguma meta de cotação. Com as intervenções estocásticas da autoridade monetária, a taxa de câmbio é, por vezes, determinada endogenamente pelos fundamentos ou manipulada pelo Banco Central. As intervenções, de tal forma, afetam as expectativas dos agentes que, ainda em períodos em que o Banco Central não atua, ocorre uma discrepância entre a taxa de câmbio e seus fundamentos. Nessa perspectiva, o modelo teórico proposto pelos autores considera os fundamentos e a intervenção, mas somente essa última variável é estadodependente. Eles afirmam ainda que, caso os dados acerca da intervenção sejam ocultos ou restritos, como é comum entre as autoridades monetárias, a probabilidade suavizada estimada fornece boas inferências se a intervenção foi conduzida em um período específico ou não. Também, se aplicado a um país específico com instrumentos de intervenção sofisticados, o modelo de mudança de regime pode ajudar a captar características especiais da dinâmica da taxa de câmbio considerada.

Já Kirikos (2002, 2004 apud LEE; CHEN, 2006) modela a taxa de câmbio com os fundamentos de mercado sujeitos à mudança de regime. Esse autor utiliza a paridade descoberta 
de juros para derivar a função objetivo da taxa de câmbio e também considera como instrumento de intervenção o gerenciamento exercido sobre o diferencial de juros.

Sarno et al. (2004) tal como Kirikos (2002, 2004 apud LEE; CHEN, 2006), utiliza os fundamentos de mercado para definir a taxa de câmbio. Todas as variáveis, explicativas e dependentes são tratadas como estado-dependentes. Esses autores investigam os desvios na relação entre taxa de câmbio do dólar americano e seus fundamentos em diferentes regimes cambiais. Já Frömmel et al. (2005) contribuem ao aplicar o modelo de mudança de regime markoviana para modelar a equação fundamental da taxa de câmbio, com os fundamentos estado-dependentes. Eles derivam um modelo monetário para a taxa de câmbio cujas variáveis explicativas são o diferencial entre a oferta de moeda, o produto nacional e as taxas de juros de longo e curto prazo domésticos e as mesmas variáveis no exterior.

Na mesma linha, Fiess e Shankar (2009) procuram avaliar como a política cambial do $\mathrm{BC}$ responde a fundamentos econômicos e financeiros. Contudo, esse trabalho se diferencia porque os regimes de câmbio (fixo, flutuante e outros) são identificados utilizando o modelo de mudança de estado markoviana.

Por fim, há também autores que aplicaram o modelo ao estudo da volatilidade da taxa de câmbio. Wilfling (2009) utilizou o modelo de mudança de regime markoviana para avaliar se a volatilidade da taxa de câmbio se alterou após o ingresso de países europeus na União Monetária Europeia (UME) e Walid et al. (2011) examinou a relação entre a volatilidade dos preços das ações e as mudanças na taxa de câmbio em países emergentes.

Em síntese, a taxa de câmbio é uma série não estacionária que apresenta longas oscilações o que provoca dificuldades teóricas na compreensão e modelagem de seus determinantes. Considerando que as altas e baixas da taxa de câmbio são governadas por um processo, uma lei de probabilidade, não observada e originada de uma Cadeia de Markov, então é possível segmentar a série em trechos de tendência estocástica. Essa é a ideia básica do Markov Switching (ENGEL; HAMILTON, 1990).

\subsection{Fundamentos do câmbio}

Para a estimação do modelo de mudança de regime para a taxa de câmbio, inicialmente faz-se necessária a identificação de uma função objetivo (modelo estrutural) que defina essa variável. Para esse fim, nesta seção abordam-se trabalhos empíricos que contribuem na identificação dos fundamentos aplicáveis à Economia brasileira. 
Em um breve retrospecto acerca do que versa a literatura internacional que trata da taxa de câmbio fundamental, Nikolsko-Rzhevskyy e Prodan (2012) afirmam que as estruturas de fundamentos nos quais se baseiam os modelos são muito similares entre os estudos e são tipicamente representadas por funções lineares consistindo em duas partes: um termos constante que caracteriza a divergência permanente entre as duas economias em questão no período da amostra e uma função macroeconômica com os fundamentos, o que caracteriza o desequilíbrio temporário que varia com o tempo. Exemplos recentes seriam Clark e West (2006) que utilizaram a paridade descoberta da taxa de juros, Gourinchas e Rey (2007) que usaram a proporção de exportações líquidas em relação aos ativos externos líquidos para prever a taxa de câmbio, Molodtsova et al. $(2008,2011)$ que se basearam na regra de Taylor e Engel et al. (2007) que tem por base fundamentos monetários e a paridade do poder de compra.

Tratando da Economia brasileira, Muinhos et al. (2002) construíram um modelo estrutural de pequena escala no qual a equação de previsão da taxa de câmbio nominal deriva da condição de paridade descoberta de juros. Os autores argumentam que, embora a relação de paridade seja originada por meio de condições de arbitragem de títulos no exterior e no país, resultados indicam que ela não é observada empiricamente. Portanto, partindo dessa relação, são realizadas adaptações e incrementadas variáveis a fim de que tenha maior respaldo empírico. Os fundamentos considerados são a taxa de câmbio nominal defasada em um período, o diferencial de juros doméstico e externo (Taxa Selic - Federal Funds rate), o prêmio de risco soberano (spread entre o rendimento do C-Bond em relação ao US Treasury) e o diferencial de inflação (IPCA - PPI americano).

A justificativa para o diferencial de juros como fundamento pode ser encontrada na possibilidade de arbitragem criada. Os investidores internacionais têm nos altos juros praticados nas economias a possibilidade de auferir ganhos de capital em operações de arbitragem, nas quais são tomadores de recursos a baixo custo em uma ponta e aplicadores em economias que apresentam melhor remuneração. Nessa operação, os ganhos pelo spread de juros motivam movimentos unidirecionais do fluxo de liquidez internacional para os países que praticam maiores taxas de juros. Por sua vez, a entrada massiva de recursos gera fortes pressões para apreciação da taxa de câmbio doméstica. Considerando a realidade da Economia brasileira, no âmbito do mercado à vista de câmbio, essas pressões podem ser mitigadas se o excesso de recursos for esterilizado nas operações de liquidez realizadas pelo BCB. As autoridades monetárias e fiscais também podem exercer controle de entrada de capitais ou ainda medidas de natureza fiscal, como a tributação de IOF. Outra possibilidade de arbitragem aparece no 
ambiente de bolsa de valores, o mercado de derivativos de juros e de câmbio profundo conjunto as altas taxas de juros favorecem os ganhos, atraindo investidores de todo o mundo. Quanto ao prêmio de risco, os investidores estrangeiros exigem remuneração adicional para investir em economias que apresentam risco de default, evidenciado pelas agências de rating.

Já em relação ao diferencial de inflação, Rossi (2013) sugere que em países cuja exportação é fortemente pautada em commodities, o ciclo de preços desses produtos exerce grande impacto sobre a taxa de câmbio. São as moedas denominadas commodity currencies. Observa-se que os setores que produzem bens industriais tendem a ajustar as quantidades frente a choques de demanda, ao passo que os setores produtores de commodities ajustam os preços. Disso decorre que a receita de exportação de um país produtor de commodities tende a ser mais volátil que de um país exportador de bens industriais, refletindo a mesma volatilidade na oferta de divisas oriundas do comércio exterior. Fernandes (2013) indica que essa característica seria verificada, por exemplo, no real, no dólar australiano, dólar canadense, rand sul-africano, peso chileno, peso mexicano, coroa norueguesa e dólar neozelandês.

Também Rossi (2013) sugere que o padrão de flutuação cambial do real acompanha o ciclo de liquidez internacional, reproduzindo a volatilidade dos índices financeiros, o que ressalta a natureza da moeda como um ativo financeiro. Essa perspectiva denota a relevância de incorporar indicadores financeiros aos fundamentos. $\mathrm{O}$ mesmo se infere da avaliação do modelo estrutural para taxa de câmbio desenvolvido por Schwartsman e Pinheiro (2010).

O modelo de Schwartsman e Pinheiro (2010), tal como o de Muinhos et al. (2002) deriva da relação de paridade de juros descoberta. Foram aplicados como fundamentos os termos de trocas - preços das exportações relativamente às importações, a disposição global ao risco, a taxa de câmbio entre o dólar e as demais moedas globais e o diferencial de juros doméstico e internacional. As seguintes relações foram consideradas para a definição dessas variáveis: 1) termos de troca (índice CRB): o aumento dos preços dos produtos exportados frente aos preços dos produtos importados se reflete em apreciação da taxa de câmbio; 2) disposição global ao risco (índice VIX): para países emergentes como o Brasil, o aumento da disposição ao risco conduz a apreciação conduz a apreciação da taxa de câmbio; 3) taxa de câmbio do dólar (índice DXY): a taxa de câmbio brasileira frente ao dólar sofre influências do valor do dólar frente às demais moedas do mundo.

Schwartsman e Pinheiro (2010) também testam os efeitos do IOF sobre a taxa de câmbio, inserindo-o como variável dummy no modelo, entretanto não encontraram significância. Acerca das demais variáveis, Schwartsman e Pinheiro (2010) concluíram que os 
grandes determinantes da taxa de câmbio brasileira são os preços das commodities e a taxa de câmbio entre o dólar e as principais moedas do mundo. A disposição global ao risco e o diferencial de juros tiveram menor influência.

\subsection{Intervenção no mercado de moeda}

O BCB pode utilizar instrumentos tradicionais de intervenção, como a intervenção sobre operações prontas e taxa de juros, como também pouco usuais como títulos públicos indexados ao câmbio e derivativos, entre outras inovações. Essas intervenções podem alterar tanto o nível ou a volatilidade da taxa de câmbio. Nesta seção discutem-se trabalhos que contribuem para a compreensão e definição dos instrumentos de intervenção.

Oliveira e Plaga (2011) avaliaram a eficácia dos instrumentos de intervenção utilizados pelo Banco Central do Brasil sobre a volatilidade da taxa de câmbio nominal. Foram utilizadas bases diárias de janeiro de 1999 a setembro de 2006. As variáveis utilizadas para a explicação da volatilidade da taxa de câmbio foram a taxa de câmbio defasada em período, a taxa de juros doméstica e as intervenções do BCB no mercado à vista, de swaps e de títulos cambiais. Como base de dados para essas variáveis foram utilizados, respectivamente, a taxa de câmbio R\$/US\$ na ponta compra, disponibilizada pelo BCB; a taxa Selic tendo por fonte o BCB; para a intervenção no câmbio à vista foi utilizado uma proxy, a série de Fatores Condicionantes da base monetária - Operações com o setor externo; já os dados de intervenção com swaps e de títulos públicos foram obtidas a partir de estimações pautadas nas séries de estoque de swaps e de títulos cambiais, o NBC-E e NTN-D. A análise foi realizada em subperíodos classificados conforme a existência de crise cambial. Os autores encontraram que ao longo de todo o período alguma forma de intervenção afetou a volatilidade condicional da taxa de câmbio nominal.

Da Rosa Borges e Júnior (2010) analisaram se as intervenções do BCB no mercado cambial introduziam algum tipo de previsibilidade no comportamento da taxa de câmbio. Foram utilizadas informações diárias de janeiro de 2004 a setembro de 2009. Os autores utilizaram regras de negociação baseadas na análise técnica para avaliar a previsibilidade com e sem intervenção. A intervenção, datas e volumes, foram estimados a partir de impactos das operações oficiais de câmbio na base monetária, informação disponibilizada pelo BCB. A taxa de câmbio utilizada foi Ptax 800 cotação venda; para o diferencial de juros foram utilizadas as remunerações dos Certificados de Depósito Bancário (CDI) divulgados pela Central de Liquidação e Custódia (Cetip) e a taxa de juros americana, o Federal Funds Rate, divulgada 
pelo Banco de Reserva Federal (Fed). Os resultados indicaram que as intervenções oficiais geram previsibilidade na taxa de câmbio.

Fernandes (2013), em um caminho inverso dos autores anteriormente citados, avaliou as razões que levam o BCB a intervir no mercado de câmbio. Foi utilizada uma série de dados diária de janeiro de 2000 a junho de 2012 e considerados como instrumentos de intervenção as operações à vista, os swaps cambiais, os empréstimos em moeda estrangeira e as linhas com recompra, contabilizados no dia do leilão. As três primeiras variáveis tiveram por fonte a $\mathrm{MCM}$ Consultoria e as demais, foram extraídas do histórico de comunicados do BCB. As estimações se deram por modelo Logit binário e ordenado, tendo por variáveis controle o nível da taxa de câmbio, seu desvio em relação à tendência e sua volatilidade, o Ibovespa, o CBOE Volatility Index (VIX), Dollar Index Spot (DXY), o spread dos títulos coorporativos de maior risco contra o título dez anos do Governo americano, prêmio de risco (Credit Default Swap - CDS), o estoque diário de reservas e uma cesta de moedas pares. Os resultados indicaram que o BCB parece reagir a todas essas variáveis, entretanto de forma assimétrica.

Além dessas intervenções realizadas pelas autoridades monetárias, no período recente, também foram utilizadas medidas de controle fluxos de capitais, por meio de regulamentações, regulação sobre a posição dos bancos e taxação sobre operações de derivativos, como o aumento do compulsório e das alíquotas do IOF.

Acerca dessa perspectiva, Munhoz (2013) verificou se a cobrança mais alta do IOF gerou impactos relevantes sobre os fluxos financeiros mais voláteis no período de 1995 a 2011. Como proxy para o IOF foi utilizada receita bruta de arrecadação desse imposto sobre operações cambiais, diferentemente de Schwartsman e Pinheiro (2010) que utilizam os valores das alíquotas. Também Silva e Resende (2010) ao avaliar a eficácia dos controles de capitais utiliza a arrecadação do IOF, entretanto, são trabalhadas separadamente as séries de arrecadação de IOF sobre entrada e saída de moeda. O autor encontrou pouca eficácia do controle de capitais via IOF.

\subsection{Modelo de Mudança de Regime}

Conforme Hamilton (1989, 1990, 1996), muitas séries econômicas exibem quebras em seu comportamento associadas a eventos tais com crises financeiras ou mudanças abruptas nas políticas do Governo. Essas mudanças abruptas também seriam uma característica predominante em séries financeiras. O método por ele desenvolvido, descrito a seguir, seria, 
portanto, bastante adequado para se calcular como tais mudanças refletem-se nos preços dos ativos.

Para representar uma mudança abrupta no comportamento de uma variável $y_{t}$, inicialmente supõe-se que o comportamento histórico típico dessa variável deveria ser descrito como um processo autorregressivo de primeira ordem, tal que:

$$
y_{t}=c_{1}+\phi y_{t-1}+\varepsilon_{t}
$$

Com $\varepsilon_{t} \sim N\left(0, \sigma^{2}\right)$. A equação (1) descreve adequadamente os dados para $t=1,2 \ldots$ $t_{0}$. Entretanto, considere-se que em $t_{0}$ haja uma mudança significativa no nível da média das séries, tal que, como alternativa, os dados sejam descritos como:

$$
y_{t}=c_{2}+\phi y_{t-1}+\varepsilon_{t}
$$

para $t=t_{0+1}, t_{0+2} \ldots$. Não se pode afirmar que a mudança de $c_{1}$ para $c_{2}$ na data $t_{0}$ seja um evento determinístico previsível no tempo $t=1$. Opostamente, deve existir alguma força não previsível que produziu a mudança. Portanto, ao invés de afirmar que a equação (1) rege os dados até a data $t_{0}$ e a equação (2) após essa data, pode-se considerar que há algum modelo único que engloble os dois casos, tal que:

$$
y_{t}=c_{s t}+\phi y_{t-1}+\varepsilon_{t}
$$

Em que $s_{t}$ é uma variável aleatória que assume valores $s_{t}=1$ para $t=1,2 \ldots t_{0}$ e $s_{t}=2$ para $t=t_{0+1}, t_{0+2} \ldots$.Uma descrição completa da lei de probabilidade que rege os dados observados requereria um modelo probabilístico do que causou a mudança de $s t=1$ para $s t=$ 2. Isso pode ser simplificado considerando que tal especificação $s_{t}$ é uma Cadeia de Markov com dois estados, na qual

$$
\operatorname{Pr}\left(s_{t}=j \mid s_{t-1}=i, s_{t-2}=k \ldots y_{t-1}, y_{t-2}, \ldots\right)
$$

Assume-se que não é possível observar $s_{t}$ diretamente, mas apenas inferir seu comportamento partir do comportamento observado de $y_{\mathrm{t}}$. Dessa forma, os parâmetros necessários para a descrição completa da lei de probabilidade que rege $y_{\mathrm{t}}$ são as variâncias da inovação Gaussiano $\sigma^{2}$, o coeficiente autorregressivo $\phi$, os dois interceptos $c_{1}$ e $c_{2}$ e as duas probabilidades de transição $p_{11}$ e $p_{22}$. Retomando que, sendo uma Cadeia de Markov, na especificação da equação (4) a probabilidade de uma mudança no regime depende do passado somente por meio do valor do regime mais recente. 
Dadas as considerações de que $y_{\mathrm{t}}$ seja observado diretamente mas que apenas seja possível fazer inferências sobre o valor de $s_{\mathrm{t}}$ baseado no que acontece com $y_{\mathrm{t}}$, a inferência tomará a forma de duas probabilidades

$$
\xi_{j t}=\operatorname{Pr}\left(s_{t}=j \mid \Omega_{t} ; \theta\right)
$$

Para $j=1,2$, por construção, essas duas probabilidades somam a unidade, $\Omega_{t}=\left\{y_{t}, y_{t-1}, \ldots, y_{1}, y_{0}\right\}$ denota o conjunto de observações obtidas dos dados no tempo $t$ e $\theta$ é o vetor dos parâmetros populacionais, os quais, para o exemplo acima são $\theta=$ $\left(\sigma, \phi, c_{1}, c_{2}, p_{11}, p_{22}\right)^{\prime}$. A inferência é realizada de forma iterativa para $t=1,2, \ldots T$, com o a etapa $t$ aceitando como input os valores

$$
\xi_{i, t-1}=\operatorname{Pr}\left(s_{t-1}=i \mid \Omega_{t-1} ; \theta\right)
$$

Para $i=1,2$ e produzindo com resultado da equação (6). Para as iterações são necessárias as funções densidade de probabilidade sob os dois regimes:

$$
\eta_{j t}=f\left(y_{t} \mid s_{t}=j ; \Omega_{t-1} ; \theta\right)=\frac{1}{\sigma \sqrt{2 \pi}} \exp \left[-\frac{\left(y^{t}-c_{j}-\phi y_{t-1}\right)^{2}}{2 \sigma^{2}}\right]
$$

Para $j=1$, 2. Especificamente, dada a input da equação (6) é possível calcular a função de densidade condicional da $t$-ésima observação por

$$
f\left(y_{t} \mid \Omega_{t-1} ; \theta\right)=\sum_{i=1}^{2} \sum_{j=1}^{2} p_{i j} \xi_{i, t-1} \eta_{j t}
$$

E o resultado será

$$
\xi_{j t}=\frac{\sum_{i=1}^{2} p_{i j} \xi_{i, t-1} \eta_{j t}}{f\left(y_{t} \mid \Omega_{t-1} ; \theta\right)}
$$

Como resultado da execução dessa iteração, será obtida a log verossimilhança dos dados observados

$$
\log f\left(y_{1}, y_{2}, \ldots, y_{T} \mid y_{0} ; \theta\right) \sum_{i=1}^{T} \log f\left(y_{t} \mid \Omega_{t-1} ; \theta\right)
$$

Para valores específicos de $\theta$. Uma estimação do valor de $\theta$ pode ser obtido maximizando a equação (10) por otimização numérica.

Várias opções são válidas para o valor $\xi_{i 0}$, usado como ponto inicial dessa iteração. Se se pressupõe a Cadeia de Markov ergótica, podem ser utilizadas as probabilidades condicionais 


$$
\xi_{i 0}=\operatorname{Pr}\left(s_{0}=i\right)=\frac{1-p_{j j}}{2-p_{i i}-p_{j j}}
$$

\subsection{Modelo de Mudança de Regime para a taxa de câmbio}

Conforme já discutido nas seções anteriores, a dinâmica da taxa de câmbio pode ser modelada como sujeita a mudanças de estado markovianas, em que os estados são não observáveis.

A ideia básica da aplicação do modelo de mudança de regime markoviana à série de taxa de câmbio é decompor essa série temporal não estacionária em uma sequência de tendências estocásticas segmentadas (ENGEL; HAMILTON,1990).

Seguindo Hamilton (1989, 1990, 1996) e Yuan (2011), tomando a equação 12, considerando $y_{t}$ o logaritmo natural da taxa de câmbio no período t e supondo que a média e a variância são regidos pelo estado não observado $s t$, tem-se que:

$$
y_{t}=c_{s t}+\phi y_{t-1}+\sigma_{s t} \varepsilon_{t}
$$

Pode-se considerar um modelo estrutural para a taxa de câmbio, no qual essa variável é definida por determinantes macroeconômicos $x_{t}$, o que transforma a equação (13) como a seguir:

$$
y_{t}=c_{s t}+\phi x_{t}+\sigma_{s t} \varepsilon_{t}
$$

Por sua vez, tal como em Lee e Chen (2006), Sarno et al. (2004), Frömmel et al. (2005) e Fiess e Shankar (2009), entre os determinantes macroeconômicos $x_{t}$, podem ser considerados o vetor de fundamentes $F_{t}$ e as intervenções das autoridades monetárias $I_{t}$, de forma que se obtém:

$$
x_{t}=\gamma F_{t}+\delta I_{t}
$$

E, portanto,

$$
y_{t}=c_{s t}+\alpha F_{t}+\beta I_{t}+\sigma_{s t} \varepsilon_{t}
$$

Em que $\alpha=\phi \gamma$ e $\beta=\phi \delta$.

Considerando as hipóteses a serem testadas, é coeso considerar as variáveis estocásticas intervenção e fundamentos estado-dependentes, de forma que mudança markoviana de estado em função da intervenção e redução no poder explicativo dos fundamentos a cada estado $s_{t}$ 
podem indicar alteração de regime de política cambial. Dessa forma, o modelo a ser estimado fica como a seguir:

$$
\begin{gathered}
y_{t}=c_{s t}+\alpha_{s t} F+\beta_{s t} I_{t}+\sigma_{s t} \varepsilon_{t} \\
F=f(\text { diferencial de juros, prêmio de risco, inflação }) \\
I=(\text { pronto, empréstimos, recompra, swap, títulos cambiais, IOF) }
\end{gathered}
$$

\subsection{Descrição dos dados e análise preliminar}

São utilizadas as séries de dados para o período de janeiro de 2004 a dezembro de 2012, em periodicidade mensal. A alternativa por esse corte temporal ocorre por permitir a captação e comparação de possíveis alterações no comportamento, volatilidade e/ou nível, da taxa de câmbio para o período anterior e pós-crise financeira internacional de 2008. Quanto ao início da série, esse foi escolhido com fins a excluir os efeitos da crise de confiança de 2001-2002. A seguir são apresentadas as bases de dados de cada variável, como também é realizada uma análise preliminar de sua capacidade de explicação da taxa de câmbio.

\section{I - Câmbio Nominal (tx.cambio):}

Como base de dados de taxa de câmbio nominal é utilizada a série Real/Dólar americano, cotação de fechamento na venda, na modalidade Ptax 800. Essa série é disponibilizada pelo BCB no Sistema Especial de Informações do Banco Central - Sisbacen. Os dados mensais de câmbio são calculados pelo BCB como média aritmética simples das cotações de fechamento diárias da moeda. A fim de considerar relações lineares entre as variáveis, a série de taxa de câmbio está logaritmizada.

Na figura 2 é apresentada a séries da taxa de câmbio para o período da amostra. Notase a não estacionariedade da série, muita volatilidade e mudanças de nível. Observa-se também o que parece ser uma quebra no comportamento da série a partir de meados de 2008. 


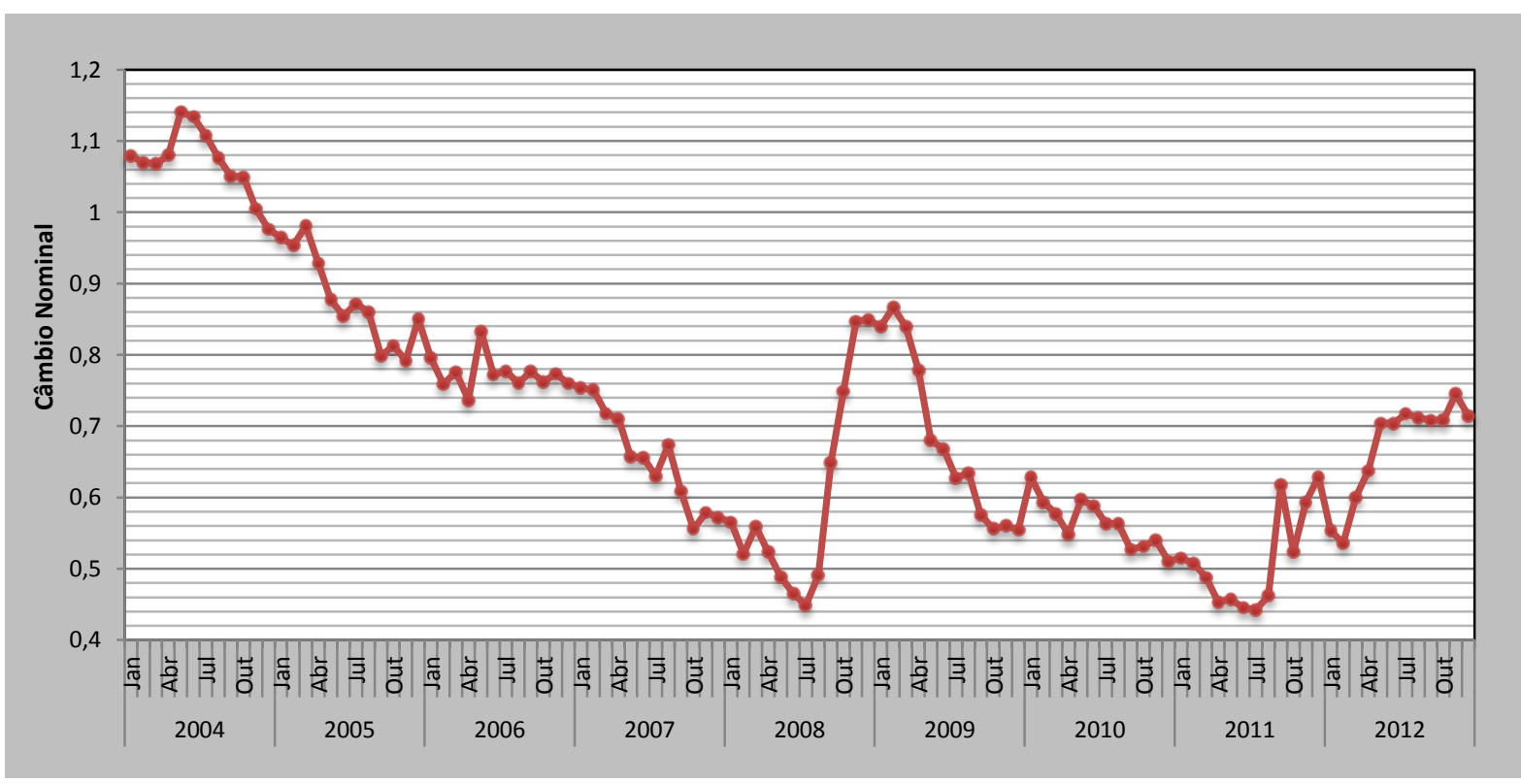

Figura 2: Dinâmica da taxa de câmbio nominal (Ptax 800 R \$/US\$) mensal de jan./2004 a dez./2012 (logaritmo natural)

Fonte: Banco Central do Brasil (2013b)

\section{II - Fundamentos da taxa de câmbio}

a) Diferencial de taxa de juros (dif.juros)

Como argumentado por Muinhos et al. (2002) ocorre a possibilidade de as corretas taxas de juros nominal doméstica e estrangeira para o modelo, serem combinações lineares de vários ativos brasileiros e americanos. Por esse motivo, para no modelo é utilizado o diferencial entre as taxas de juros efetivas do Federal Funds $\left(F f u n d s_{t}\right)$ e a taxa over Selic efetiva $\left(\right.$ Selic $\left._{t}\right)$, por essas serem construídas a partir das médias das taxas realizadas diariamente e, portanto, serem referencial do comportamento das taxas no mercado. Outro ponto importante, como as séries serão trabalhadas a nível mensal, apesar de a teoria da paridade de juros versar sobre uma defasagem de efeito das taxas que proporcionaram as condições de arbitragem e seus efeitos sobre a variação cambial, aqui essa defasagem não será considerada, visto a alta periodicidade dos dados. O diferencial de juros (dif.juros ${ }_{t}$ ) para um dado tempo $t$ é obtido conforme equações 19 e 20 :

$$
\begin{gathered}
\text { dif.juros }{ }_{t}=\ln \left(\frac{\text { Selic }_{t}}{\text { Ffunds }}\right) \\
\text { dif.juros } \\
t=\ln \left(\text { Selic }_{t}\right)-\ln \left(\text { Ffunds }_{t}\right)
\end{gathered}
$$

Em que, 
$\ln \left(\right.$ Selic $\left._{t}\right)=\operatorname{logaritmo}$ natural da taxa Overnight/Selic efetiva mensal (\%a.a.), disponibilizada pelo Ipeadata $(\ln (1+$ Selic $\%))$.

$\ln \left(\right.$ Ffunds $\left._{t}\right)=$ logaritmo natural da Federal Funds Rate efetiva mensal (\%a.a.), disponibilizada no sítio eletrônico do Federal Reserve Bank of St. Louis $(\ln (1+$ Ffunds\%)).

Na figura 3 (a) apresenta-se a plotagem das séries do logaritmo natural das taxas de câmbio e do diferencial de juros e na figura 3 (b) a correlação entre essas variáveis. Infere-se uma dinâmica próxima entre as séries, com sentido ora positivo ora negativo, portanto não linear.

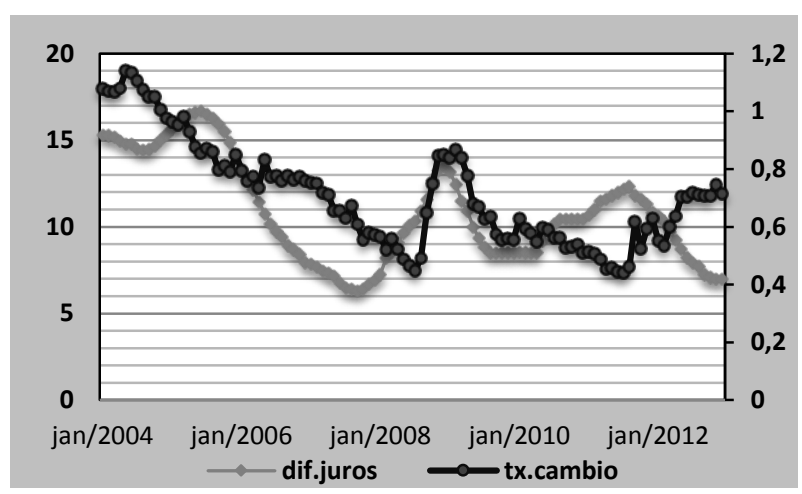

(a) dinâmica do diferencial de juros (esquerda) vs ln da taxa de câmbio (direita)

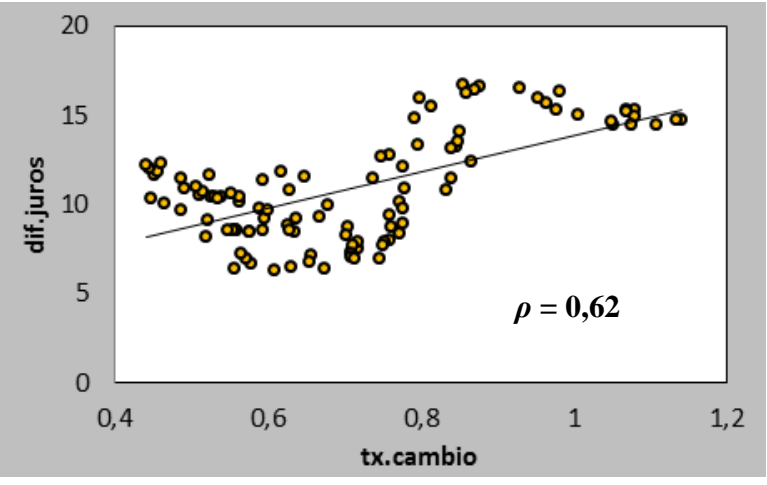

(b) diagrama de dispersão: diferencial de juros $v s$ taxa de câmbio

Figura 3: Correlação entre diferencial de juros e o $\ln$ da taxa de câmbio - jan./2004 a dez./2012 Nota: $\rho=$ Coeficiente de correlação de Pearson

Fonte: Elaboração própria

\section{b - Prêmio de risco soberano (pr)}

Muinhos et al. (2002) utilizam como prêmio de risco o diferencial entre o C-Bond e o US Treasury e argumentam ter utilizado o C-bond por três razões: primeiro, por ser o título com a série mais longa disponível à época do estudo; segundo, por vencer em abr./2014, seu preço não está viesado pela proximidade do vencimento; e terceiro, o poder de explicação do spread do C-Bond foi melhor que o de outras medidas de risco testadas. Já Fernandes (2013) utiliza o prêmio de risco (Credit Default Swap - CDS), sendo essa uma medida muito utilizada como referência no mercado. Pela restrição na obtenção da série de CDS, aqui foi seguida a perspectiva de Muinhos et al. (2002). Entretanto, dada a proximidade de maturidade do CBond, é considerado o spread entre o Bônus Global República (40) e os títulos de dívida 
americana de mesmo vencimento, em pontos base ${ }^{2}$. O Bônus global República (40) tem vencimento para 2040.

Na figura 4, observa-se dinâmica muito próxima entre os movimentos da taxa de câmbio e do prêmio de risco soberano, o que é evidenciado pelo alto coeficiente de correlação entre as séries (0,77). Para alguns períodos, entre 2007 e 2008 e fim de 2012, a relação entre os dados parece converter para negativa. Observam-se também, pelo diagrama de dispersão, fortes indícios de relação linear entre as variáveis.

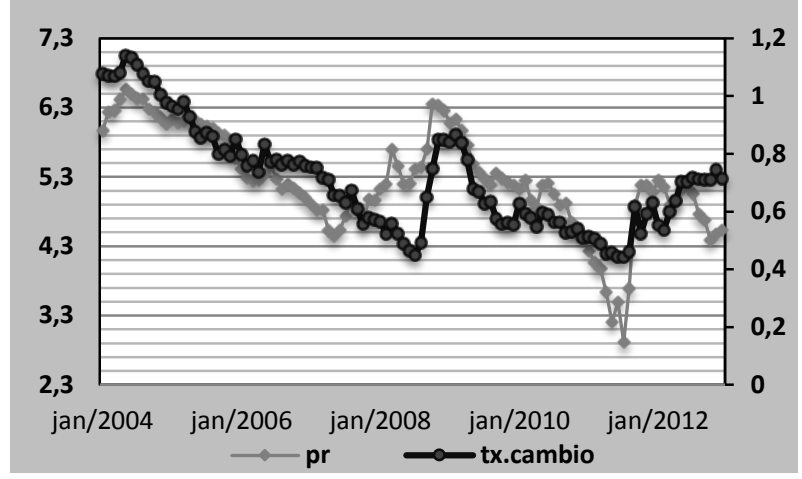

(a) dinâmica do prêmio de risco soberano (esquerda) $v s \ln$ da taxa de câmbio (direita)

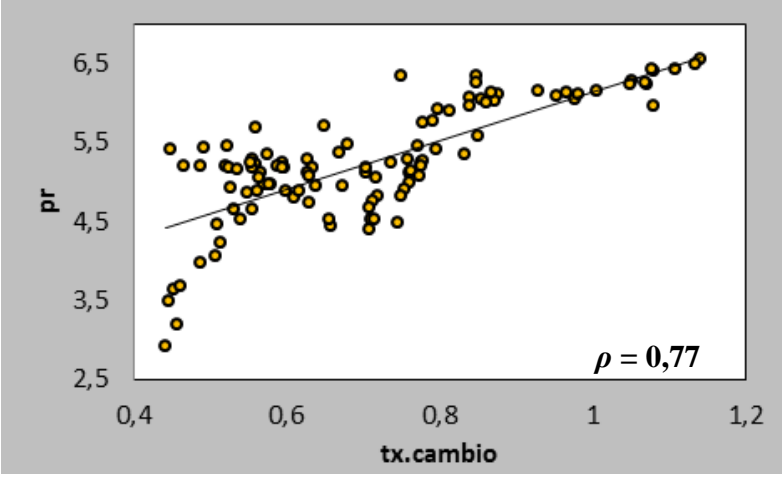

(b) diagrama de dispersão: prêmio de risco vs taxa de câmbio

Figura 4: Correlação entre o prêmio de risco soberano e o ln da taxa de câmbio - jan./2004 a dez./2012

Nota: $\rho=$ Coeficiente de correlação de Pearson

Fonte: Elaboração própria

c - inflação (Icrb)

Como observado na bibliografia, o diferencial de inflação é relevante fundamento para a taxa de câmbio, como também os índices internacionais de preços de commodities, considerada a moeda brasileira uma commodity currency. Entretanto, ocorre que essas duas variáveis possuem alta correlação entre si $(0,85)$, uma vez que ambas representam preços e os preços domésticos sofrem grande impacto dos produtos comoditizados. Dessa forma, pelo índice de preço de commodities permite captar, além do efeito preço, mas também a relação entre os termos de troca e a taxa de câmbio, essa é a variável utilizada. A série foi obtida no sítio eletrônico do Commodity Research Bureau.

\footnotetext{
${ }^{2}$ O Ipeadata disponibiliza a série de spread que é calculado pelo Valor Econômico. É utilizada essa base de dados em logaritmo natural.
} 
Para fins de comparação, na figura 5 são apresentadas ambas as séries, de diferencial de inflação e o índice de preços de commodities, comparadas a série de câmbio e em diagrama de dispersão. As duas variáveis possuem forte correlação com a taxa de câmbio e indicam ser bem modeladas por relações lineares.
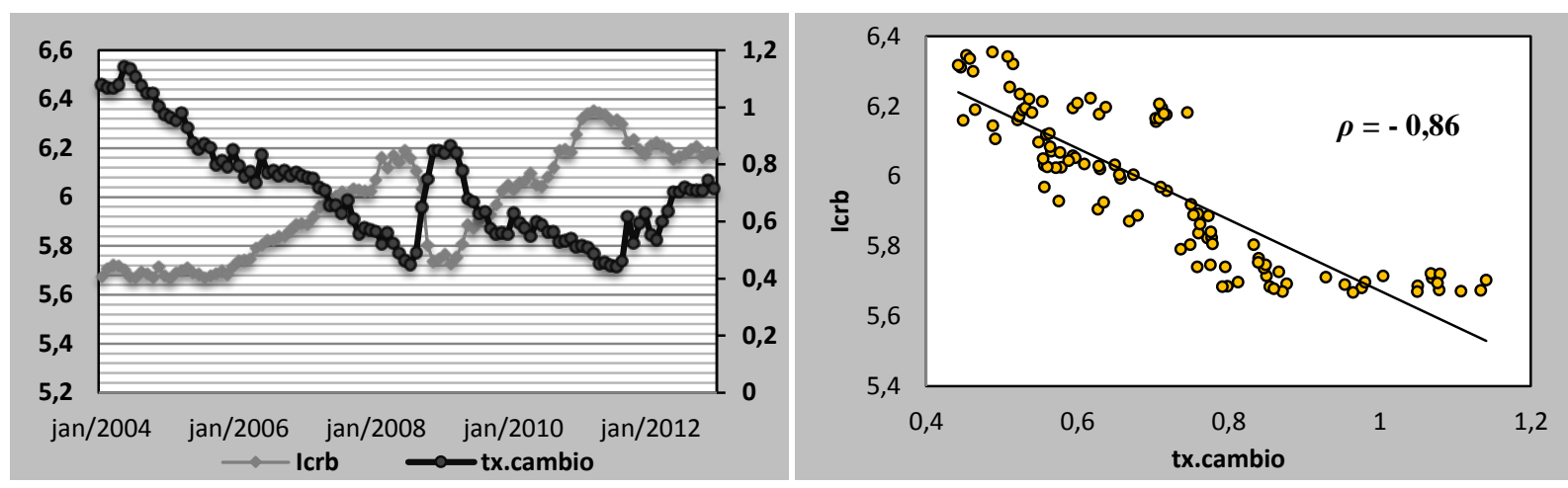

(a) dinâmica do índice de preços de (b) diagrama de dispersão: índice de preços de commodities (esquerda) vs ln da taxa de commodities vs taxa de câmbio câmbio (direita)

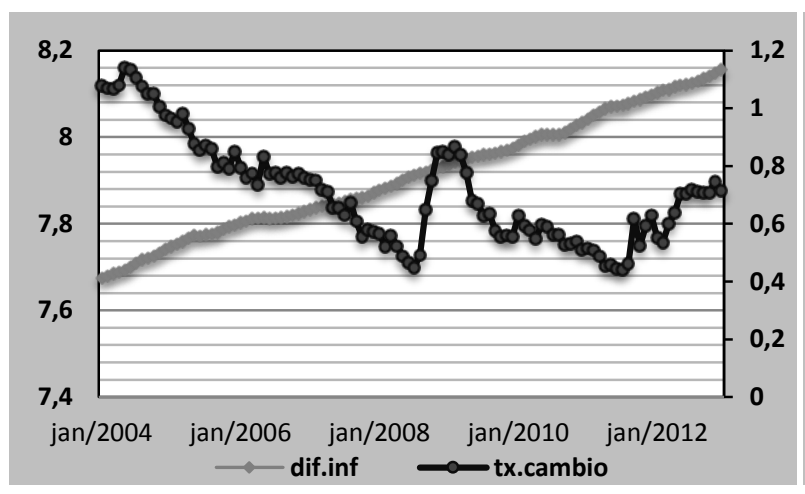

(c) dinâmica do diferencial de inflação (esquerda) vs ln da taxa de câmbio (direita)

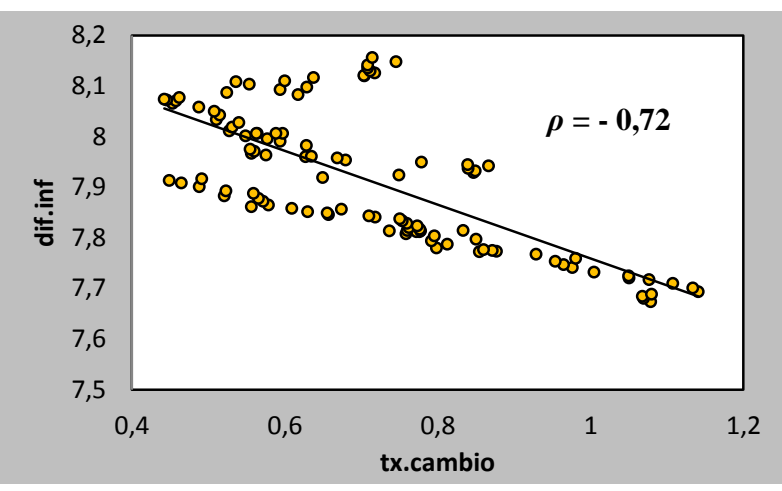

(d) diagrama de dispersão: diferencial de inflação $v s$ taxa de câmbio

Figura 5: Correlação entre o diferencial de inflação, o índice internacional de preços de commodities e o $\ln$ da taxa de câmbio - jan./2004 a dez./2012

Nota: $\rho=1$ Coeficiente de correlação de Pearson

2 Diferencial de inflação calculado pela diferença entre o IPCA/IBGE e o índice de preços ao consumidor dos Estados Unidos (série 3794 do Sisbacen)

Fonte: Elaboração própria

\section{III - Instrumentos de intervenção}

As intervenções passíveis de impacto sobre a taxa de câmbio são trabalhadas em duas variáveis distintas, sendo 1) intervenção realizada por autoridades monetárias e 2) intervenções fiscais.

1) intervenção do BCB (Interv) 
Existe no Sisbacen uma série de dados denominada 'Intervenção do BCB no mercado de câmbio', que se refere ao saldo de operações de compra e venda liquidadas no mercado de câmbio à vista. Entretanto, essa série só começou a ser produzida em 2009. Observa-se na literatura, que trabalhos que abarcam períodos anteriores a essa data utilizam variáveis proxies. Por exemplo, Oliveira e Plaga (2011), usam a série de Fatores Condicionantes da base monetária - Operações com o setor externo.

Dado que o corte temporal do presente trabalho inicia-se em 2004, é considerado um indicador de intervenção composto pelo somatório das intervenções que afetam as reservas, as intervenções sobre o mercado de derivativos e a emissão de títulos cambiais. Para esse fim, são utilizadas as seguintes séries de intervenção: 1) sobre as reservas: valor líquido de operações com moeda liquidadas pelo BCB referentes às linhas de recompra, aos empréstimos em moeda estrangeira, ao dólar pronto e as operações a termo. Essas informações foram extraídas do Demonstrativo de variação de reservas internacionais, produzido pelo BCB. Todos os dados são referentes ao fechamento em ( $\mathrm{t}$-1), logo essa variável é considerada com defasagem de um período; 2) sobre o mercado de derivativos: swap cambial, que equivale à venda no futuro de dólar e swap cambial reverso, correspondente à operação de compra. Os dados foram extraídos das notas para imprensa sobre operações no mercado aberto divulgadas pelo BCB. As informações de swaps se referem às colocações e resgates, entretanto nesse trabalho é utilizado somente os valores referentes às colocações, pois sendo o swap uma operação contratada a data e valores definidos, acredita-se que seu impacto sobre o mercado de moeda seja na data da operação e não na liquidação. Outro ponto, as operações de swap são liquidadas em reais, portanto não afetam as reservas de forma direta; 3 ) títulos cambiais: são considerados os títulos indexados ao câmbio, quais sejam o NTN-D, NTN-A, NTN-M, NTN-I, NTN-R, BTN, CRT, NBCE, NBCF e FAT CAMBIAL. Importante destacar que esses títulos não são mais emitidos, portanto, para o corte temporal desse trabalho procurou-se utilizar os dados referentes aos resgates. Foram encontradas poucas informações, pois apenas o NTN-D e o NBCE foram resgatados no período considerado e de forma pontual.

Para produzir um indicador de intervenção, essas informações foram primeiramente agregadas em operações que pressionam pela valorização cambial: vendas de dólar a termo, venda de dólar pronto, vendas com compromisso de recompra, empréstimos em moeda estrangeira e swap cambial; operações que pressionam pela desvalorização: compra de dólar a termo, compra de dólar pronto, recompra de dólar, recebimento de empréstimos em moeda estrangeira, swap cambial reverso e resgate de títulos cambiais. O segundo passo foi a obtenção 
das intervenções líquidas, fazendo a soma das operações, sendo as que desvalorizam foram consideradas positivas e as que valorizam, negativas. Esse segundo passo foi necessário, pois como as intervenções do BCB são concentradas, as séries separadamente continham muitos zeros.

Na figura 6 são apresentadas as intervenções do BCB no mercado de moedas, conforme descrito anteriormente, os números negativos referem-se às operações que, teoricamente, conduzem à apreciação da taxa de câmbio e positivos referem-se às operações conduzem a desvalorização.

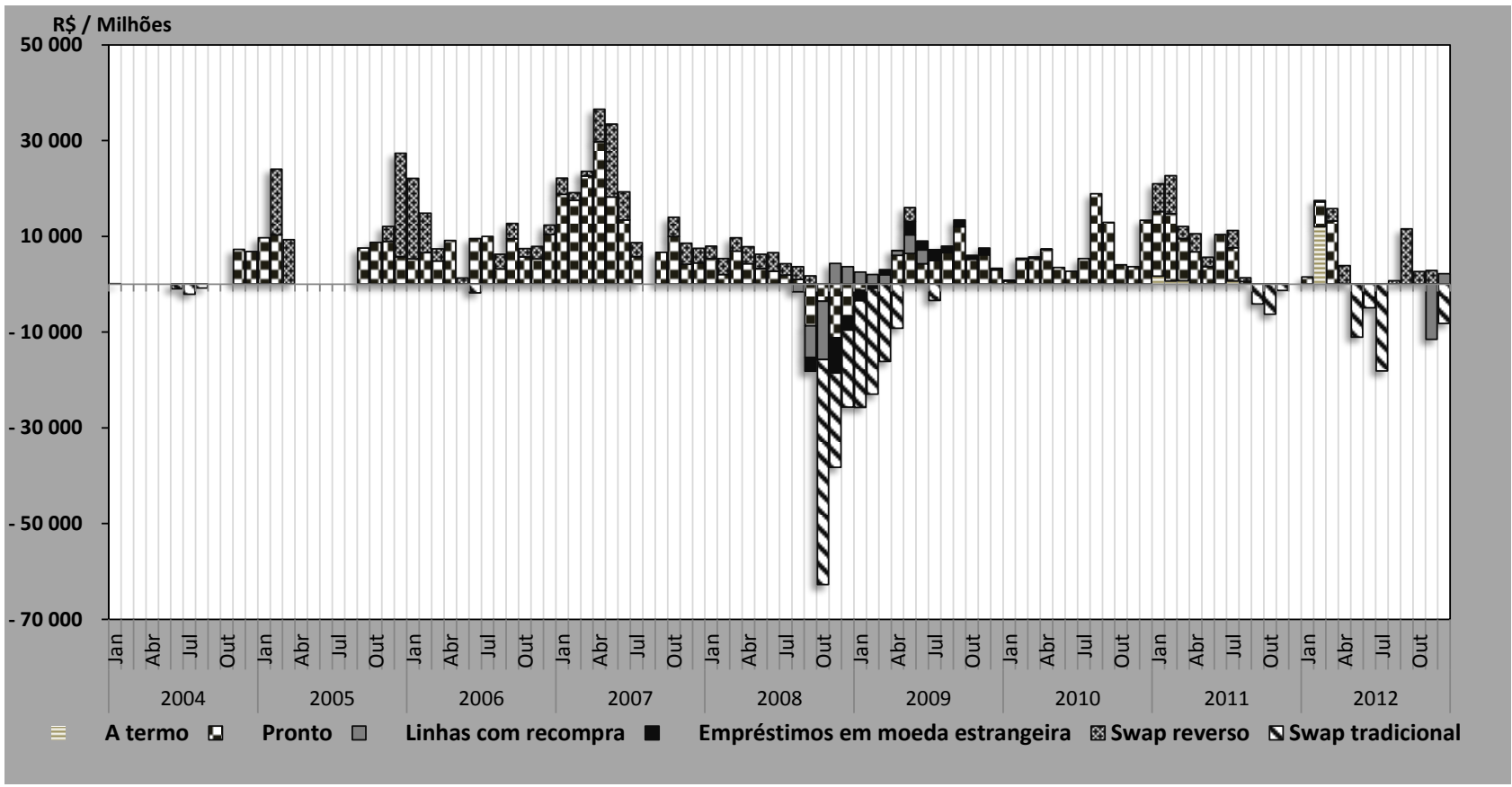

Figura 6: Volume de intervenções do BCB no mercado de moedas brasileiro em reais (milhões) por tipo de operação - jan./2004 a dez./2012

Fonte: Elaboração própria.

1) intervenções fiscais (IOF)

São variadas as inovações de política monetária e fiscal para gestão e controle do fluxo de entrada e saída de capitais que podem, e por vezes tem por intenção, impactar na dinâmica da taxa de câmbio. Entre as principais medidas está a implementação do IOF sobre a liquidação de operações de câmbio para aplicação em renda fixa, variável e entrada e saída de capitais voláteis. Conforme salientado por Munhoz (2013) e Silva e Resende (2010), é tarefa complexa considerar as informações de alíquotas na estimação de um modelo. Por esse motivo, tal como esses autores, será utilizado como proxy para as intervenções fiscais a arrecadação de IOF sobre operações de câmbio. Destaca-se que enquanto Munhoz (2013) utilizou a receita bruta de 
arrecadação, Silva e Resende (2010) utilizaram separadamente as receitas de arrecadação sobre entrada e saída de moeda. Para esse trabalho é utilizada a receita bruta de arrecadação.

\section{Resultados e discussões}

\subsection{Parâmetros estimados}

O resultado da estimação dos parâmetros, por máxima verossimilhança, do modelo fundamental para a taxa de câmbio sujeito a mudanças de estado nos fundamentos e intervenção encontra-se na tabela 2. Respectivamente, Dif.juros, Pr, Icrb, Interv e IOF, referem-se as variáveis diferencial de juros, prêmio de risco soberano, índice internacional de preço de commodities, intervenção do BCB e IOF cambial.

Foi testado o limite de estados (regimes) aceitável pelo sistema e foram identificados 3. Para mais estados não há significância nos parâmetros. Por conseguinte, foram estimados três modelos.

No modelo 1 foram consideradas todas as variáveis explicativas e 2 estados. Os estados mostram-se aderentes, uma vez que as variáveis, em geral, foram significativas na explicação da taxa de câmbio. O sistema também identificou uma mudança de nível significativa entre os dois regimes, o que se observa pela diferença entre os interceptos dos estados. Também no modelo 2 os parâmetros de todas as variáveis foram estimados, entretanto foi acrescentado um estado. Tal como no modelo 1, em geral as variáveis foram significativas para explicar os estados. Entretanto, uma observação importante é que a variável intervenção (interv) não foi significativa no modelo 1 nem no 2 em nenhum dos regimes. Visto isso, foi estimado um terceiro modelo, com 3 estados e excluída essa variável. 
Tabela 2: Estimativa dos parâmetros do modelo de mudança markoviana de regime aplicado à equação estrutural de curto prazo da taxa de câmbio nominal

\begin{tabular}{|c|c|c|c|}
\hline Modelo 1: dois estados & AIC: $-333,0523$ & BIC: $-244,6812$ & \\
\hline Parâmetro da variável & Regime 1 & Regime 2 & \\
\hline Intercepto & $8,4853(0,2227)^{* * *}$ & $1,6733(0,7626)^{*}$ & \\
\hline Dif.juros & $-0,0185(0,0041) * * *$ & $0,0350(0,0036)^{* * *}$ & \\
\hline $\operatorname{Pr}$ & $-0,0272(0,0271)$ & $0,0860(0,0221)^{* * *}$ & \\
\hline Icrb & $-1,2662(0,0391) * * *$ & $-0,3025(0,1133)^{* *}$ & \\
\hline Interv & $(0) 0$ & $(0) 0$ & \\
\hline IOF & $0,0007(0,0001)^{* * *}$ & $-0,0001(0,0001)$ & \\
\hline$p_{11}$ & 0,9611 & & \\
\hline$p_{22}$ & 0,9811 & & \\
\hline Modelo 2: três estados & AIC: $-374,3248$ & BIC: $-241,7681$ & \\
\hline Parâmetro da variável & Regime 1 & Regime 2 & Regime 3 \\
\hline Intercepto & $6,9668(0,5658)^{* * *}$ & $3,0377(0,8545)^{* * *}$ & $4,0185(0,3449) * * *$ \\
\hline Dif.juros & $-0,0214(0,0060) * * *$ & $0,0334(0,0033) * * *$ & $0,0178(0,0054) * * *$ \\
\hline $\operatorname{Pr}$ & $0,0288(0,0374)$ & $0,0653(0,0173) * * *$ & $0,0779(0,0289) * *$ \\
\hline Icrb & $-1,0504(0,0931) * * *$ & $-0,5039(0,1257) * * *$ & $-0,6742(0,0368) * * *$ \\
\hline Interv & $(0) 0$ & $(0) 0$ & $(0) 0$ \\
\hline IOF & $0,0006(0,0001) * * *$ & $-0,0001(0,0001)$ & $0,0001(0,0000)^{* * *}$ \\
\hline$p_{11}$ & 0,9490 & & \\
\hline$p_{22}$ & 0,9242 & & \\
\hline$p_{33}$ & 0,9375 & & \\
\hline Modelo 3: três estados & AIC: $-376,4652$ & BIC: $-266,0013$ & \\
\hline Parâmetro da variável & Regime 1 & Regime 2 & Regime 3 \\
\hline Intercepto & $4,7410(0,7553)^{* * *}$ & $2,8696(0,1988) * * *$ & $8,0826(1,4739) * * *$ \\
\hline Dif.juros & $0,0019(0,0047)$ & $0,0213(0,0020) * * *$ & $-0,0381(0,0053) * * *$ \\
\hline $\operatorname{Pr}$ & $0,0198(0,0237)$ & $0,0710(0,0082)^{* * *}$ & $0,0388(0,0339)$ \\
\hline Icrb & $-0,7098(0,1097) * * *$ & $-0,4470(0,0301)^{* * *}$ & $-1,1851(0,2435)^{* * *}$ \\
\hline IOF & $0,0000(0,0000)$ & $-0,0001(0,0000)^{* * * *}$ & $0,0001(0,0003)$ \\
\hline$p_{11}$ & 0,9508 & & \\
\hline$p_{22}$ & 0,9356 & & \\
\hline$p_{33}$ & 0,9090 & & \\
\hline
\end{tabular}

Fonte: Resultados da pesquisa

Nota: 1 Erro padrão entre parênteses.

2 Indicação de significância do teste $t: 0,1 \%(* * *), 1 \%(* *), 5 \%(*), 10 \%(\cdot)$

Para a seleção do modelo que melhor representa o conjunto de dados foram observadas as estatísticas de seleção Critério de Informação de Akaike (AIC) e Critério Bayesiano de Schwarz (BIC). O modelo 3 apresentou o melhor ajuste ${ }^{3}$.

Considerando o modelo 3, com três estados, observa-se significativa mudança de nível de um estado para outro, indicando mudança na média da taxa de câmbio a cada regime. Também os parâmetros das variáveis explicativas modificaram-se significativamente em valor e no sentido do impacto (de baixa, de alta) sobre a taxa de câmbio. As variáveis mostram-se significativas na explicação da dinâmica da taxa de câmbio em todos os regimes com $90 \%$ de

\footnotetext{
3 Foram testados também dois outros modelos: 1) sujeito a mudança markoviana de regime apenas nos fundamentos e 2) sujeito a mudança markoviana de regime apenas na intervenção. Para ambos não foi encontrado um bom ajuste dos dados.
} 
confiança ou mais, excetuando-se apenas o diferencial de juros, o prêmio e o IOF que não explicam o regime 1 e o prêmio e o IOF que não explicam o regime 3.

Especificamente, a transição da taxa de câmbio entre os regimes 1 e 2 (e do 2 para 1) se explica por modificações nos fundamentos. Já a transição do regime 2 para o 3 (e do 3 para 2) é explicado por todas as variáveis; já para as alterações do regime 1 para o 3 (e do 3 para o 1) também por todas as variáveis.

Dos resultados da tabela 2, observa-se também alta persistência de cada um dos regimes pelos altos valores das probabilidades de transição $p_{i i}$ - probabilidade de estar no regime $i$ e ir para o regime $j$ - entre os regimes, $p_{11}, p_{22}$ e $p_{33}$. Isso indica que se a sistema encontra-se no regime 1, ou 2 ou 3, ele provavelmente permanecerá nesse estado. O modelo permite conhecer também a duração esperada de cada estado $i$, essa é definida por $1 /\left(1-p_{i i}\right)$. Dessa forma, espera-se que o regime 1, 2 e 3, a cada ocorrência, persista por 20, 16 e 11 meses.

\subsection{Classificação dos regimes}

Na figura 7 apresenta-se a ocorrência dos três regimes de câmbio, sendo cada um a área hachurada sobre a série do log da taxa de câmbio, juntamente com a probabilidade suavizada de realização de todos eles para cada dado da amostra, na parte inferior. A probabilidade suavizada é definida como $\operatorname{Pr}\left(s_{t}=j \mid Y_{T}\right)$, ou seja, é a probabilidade de ocorrência do estado $i$ calculada com base em todas as informações da série $\left(Y_{T}\right)$ em cada momento do tempo $t$. Se o estado $\mathrm{s}_{\mathrm{t}-1}=1$ e probabilidade $p_{11}$ é alta, então é provável que a observação log da taxa de câmbio $\mathrm{y}_{\mathrm{t}}$ tenha sido gerada da distribuição 1, portanto, do estado 1, sendo que esta mesma interpretação é validada para os outros estados. Desse modo, observam-se na figura 7, os regimes de cada observação sendo determinados pelas probabilidades suavizadas de as observações $y_{t}$ estarem naquele regime. Os valores baixos de probabilidade suavizada no início e fim de cada regime (figura 7) indicam que ocorre um processo de transição entre eles.

Importante ressaltar que, apesar de a probabilidade $p_{11}$ ser definida para cada observação $y_{t}$ individualmente, ela depende dos $y$ 's e regimes dos períodos anteriores, de modo que possibilita a captação do comportamento em cluster da taxa de câmbio. De forma que a alta persistência de cada regime denotado pelas probabilidades de transição apresentada na seção anterior $\left(p_{11}, p_{22} p_{33}\right)$ e a longa duração de cada um indica que apesar da alta volatilidade da taxa de câmbio brasileira, os ciclos de mudança são longos e se intercalam. 

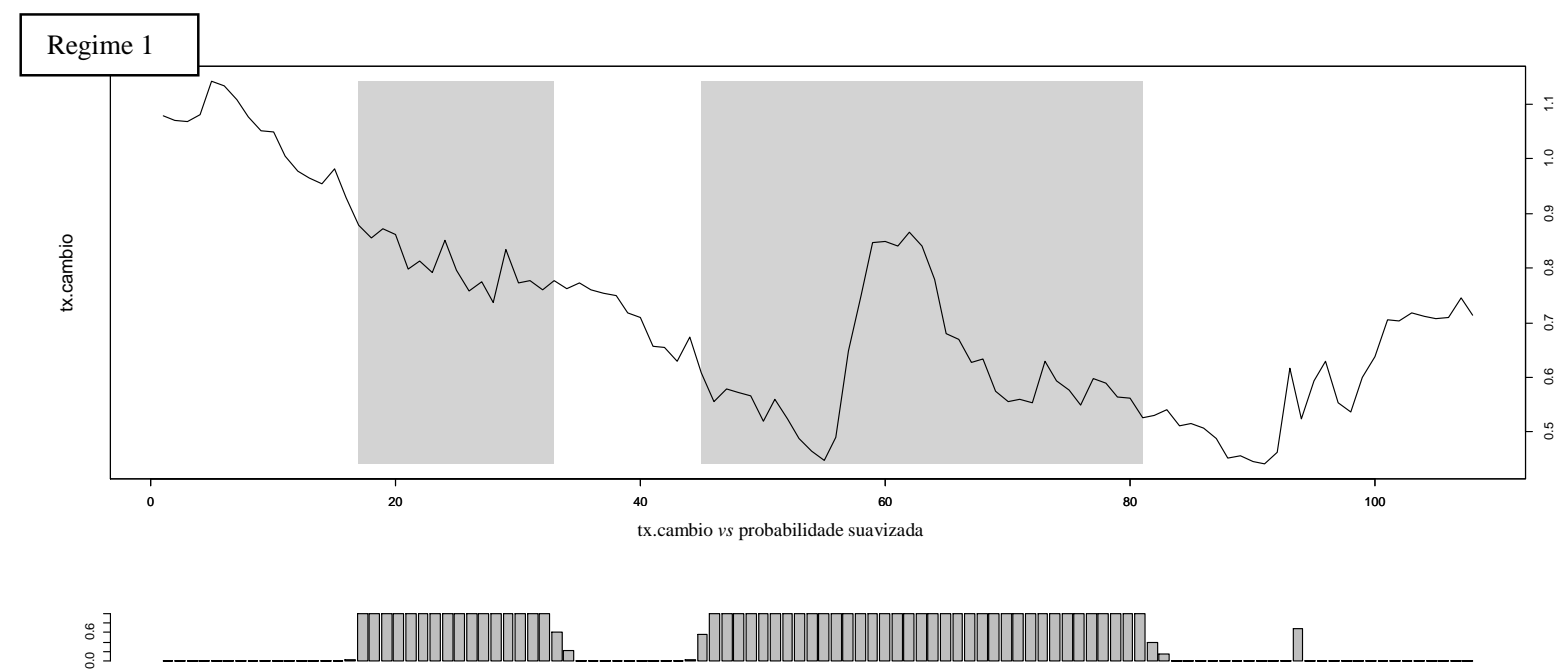

Regime 2

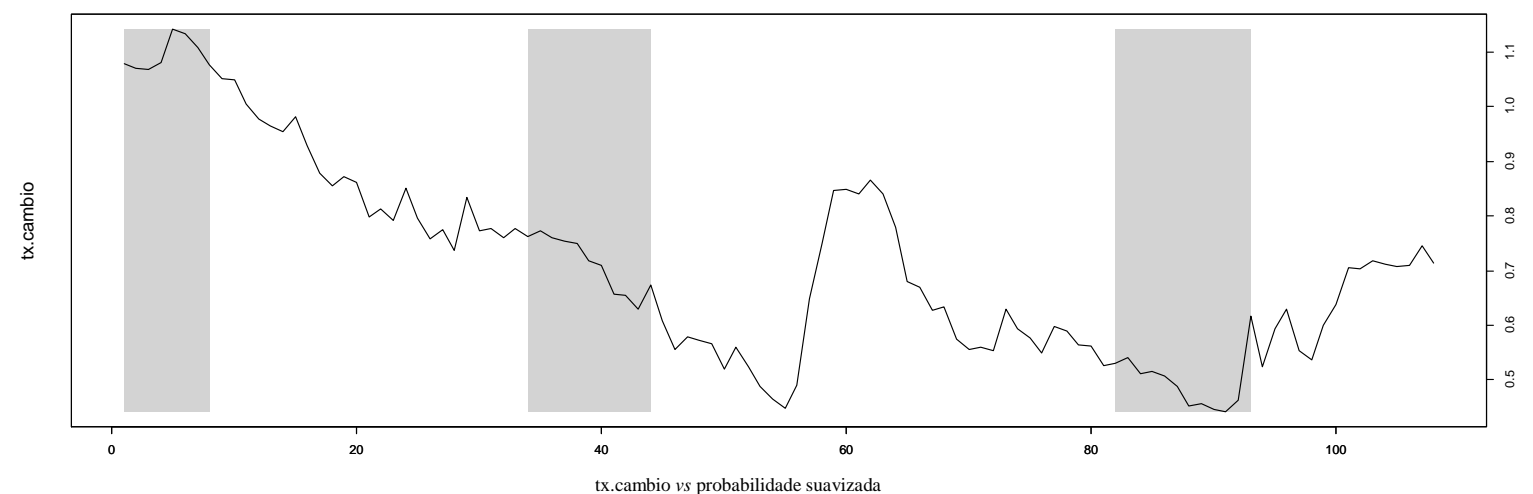

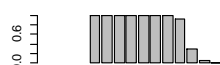

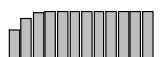

\section{Regime 3}

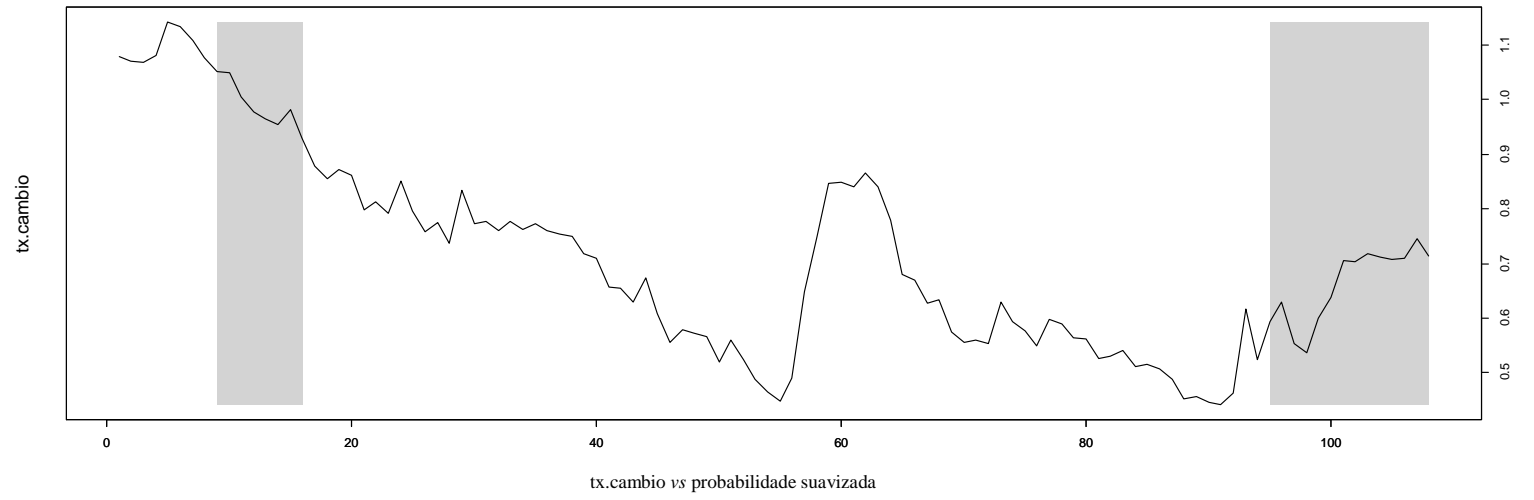

$: \exists$
$: \exists$

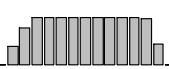

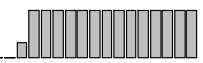

Figura 7: Probabilidade suavizada de ocorrência dos regimes markovianos para o modelo 3 por observação

Fonte: Resultado de pesquisa 
Os regimes podem ser compreendidos como ciclos da taxa de câmbio; cada um deles compreende um segmento de tendência estocástica de $y_{t}$, cuja probabilidade de estar em um deles é $s_{t}=i$ e segue distribuição normal. A literatura acerca dos regimes markovianos na taxa de câmbio geralmente atribui a existência de 2 estados, sendo interpretados como um ciclo de apreciação e outro de depreciação da moeda, tal como em Engel e Hamilton (1990), isso pela dificuldade de interpretação de um terceiro estado. Nesses casos, os autores utilizaram como variável dependente a volatilidade ou variação da taxa de câmbio. Tomando o resultado da estimação dos parâmetros (tabela 2) e da figura 7 sob essa ótica, pode se inferir que o regime 3 captou a tendência de alta (desvalorização) da taxa de câmbio, estando presente em muitos picos da cotação da moeda; o regime 2 a tendência de baixa (apreciação) e o regime 3, um período de maior volatilidade com frequentes mudanças entre períodos de alta e baixa, esse capta o período de crise internacional. Reforça essa conclusão a observação da média da taxa de câmbio em cada regime, sendo de 4,7 para o regime 1;2,9 para o regime 2 e 8,1 para o regime 3 e pelo valor do erro padrão residual de cada estado - 0,021 para 3; 0,020 para 2; 0,037 para o 1 .

A tabela 3, a seguir, apresenta a mesma análise da figura 7, conjunto a duração de cada ocorrência dos regimes. Pode-se depreender que a duração de cada regime diverge, mas em geral mantém-se próxima da duração esperada. Também como observado anteriormente, aqui se nota, à exceção do período de crise, a predominância de processos de apreciação da taxa de câmbio brasileira.

Tabela 3 - Períodos de ocorrência e duração dos regimes markovianos para o modelo 3

\begin{tabular}{cc}
\hline & \multicolumn{1}{c}{ Duração } \\
\cline { 2 - 2 } Regime 1 & $2005: 06-2006: 09(15)$ \\
& $2007: 10-2010: 09(36)$ \\
\hline Regime 2 & $2004: 02-2004: 08(7)$ \\
& $2010: 11-2011: 09(11)$ \\
\hline Regime 3 & $2004: 10-2005: 04(7)$ \\
\hline & $2011: 12-2012: 12(13)$ \\
\hline
\end{tabular}

Fonte: Resultado de pesquisa

Nota: entre parênteses a duração em meses 
Nota-se também que, se considerado o regime 1 como determinado por choques, o sistema captou um efeito da crise internacional de 2008 sobre a taxa de câmbio que persiste períodos além do fim da crise.

\subsection{Interpretação temporal do modelo e validação das hipóteses}

Na figura 8 apresenta-se em perspectiva temporal de evolução dos regimes de câmbio. Em vermelho o regime 1, em verde o regime 2 e em azul o regime 3. De forma geral, a primeira observação que se faz é acerca da aderência teórica da modelagem. Os regimes parecem ter captado bem as principais turning points da taxa de câmbio brasileira.

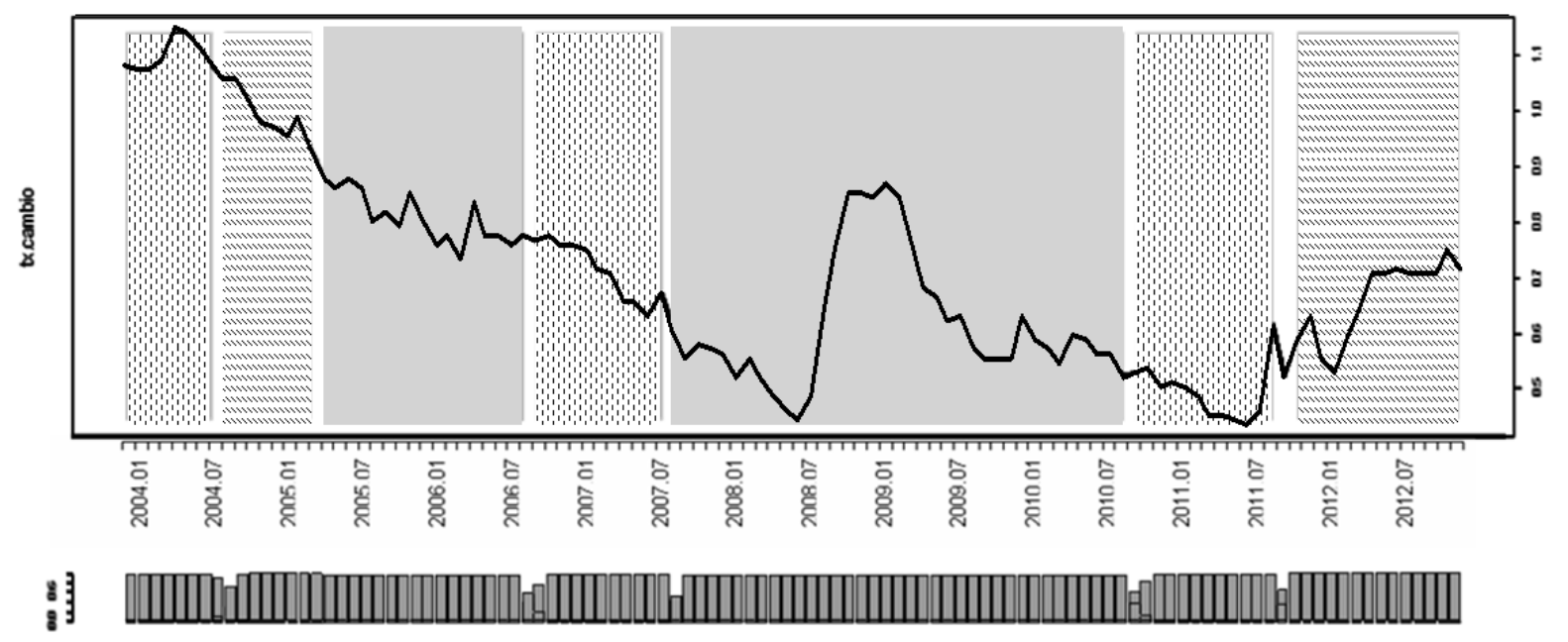

Figura 8: Perspectiva temporal de ocorrência dos regimes markovianos para o modelo 3

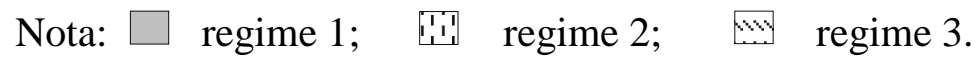

O modelo permite compreender, entre as variáveis explicativas utilizadas, quais tem contribuição significativa para a definição de dado estado. Mas essa análise deve ser vista com cuidado, pois se tratando de um modelo, não foram abarcadas todas as variáveis e interações da complexa conjuntura econômica doméstica e internacional que podem estar influenciando a dinâmica de taxa de câmbio. Nesse sentido, serão abordados e descritos os principais fatos das variáveis que auxiliam na compreensão de cada regime.

A série inicia com o regime 2 , ou seja, tendência de apreciação da taxa de câmbio brasileira, uma quebra de dinâmica ocorre no período de outubro de 2004 a abril de 2005, em que predomina a curta tendência de desvalorização (regime 1), até o sistema cambial entrar em fase de maior instabilidade, correspondente a área vermelha da figura 8. 
O modelo explica a instabilidade do estado 1, que ocorre nos períodos 1) junho de 2005 a setembro de 2006 e 2) outubro de 2007 a setembro de 2010, com a variável índice de preços de commodities. Houve um boom nos preços internacionais das commodities que se seguiu de 2005 a 2010, o que parece ter contribuído para os curtos ciclos de ganho e perda de valor da moeda nacional do estado 1. Entretanto, deve-se atentar a outros fatores, como a iminência de uma crise internacional. Do fim de 2004 ao fim 2005 tem-se o seguinte cenário: elevação da taxa de juros referencial básica americana de 1\% para 4\% a.a.. A taxa de juros chegou a 5,25\% a.a. em julho de 2006. Esse teria sido início da crise internacional, pois o aumento de juros teve efeito negativo no mercado imobiliário, os preços caíram e houve aumento da inadimplência, e, portanto, as carteiras com títulos subprime se deterioraram. Em um segundo momento, de setembro de 2007 a meados de 2009, a crise ganha proporções internacionais. Ambos os períodos parecem ter sido captados como um ciclo de maior variabilidade da taxa de câmbio, entretanto nenhuma das variáveis explicativas adotadas conseguiu captar essa dinâmica, ou seja, nem os fundamentos nem a intervenção das autoridades explicam a volatilidade da taxa de câmbio em períodos de crise. O modelo identifica a duração dos efeitos da crise internacional sobre a taxa de câmbio brasileira até setembro de 2010.

Quanto ao estado 2, com tendência de apreciação da taxa de câmbio, ocorre no início da série, entre crises (estado 1) e após a crise. A tendência de apreciação, a exceção do período atípico de crise, predomina na Economia brasileira para o período de amostra considerado. Todas as variáveis explicativas foram significativas na explicação desse regime.

Interessante observar que as intervenções fiscais com o IOF influenciam o valor da taxa de câmbio durante esse regime, o que não necessariamente é sinal de eficácia, visto a pequena sensibilidade observada pelo parâmetro, e a pressão apreciativa que exerce sobre a cotação da moeda, ou seja, a política teve efeito cíclico, oposto ao desejado pelas autoridades.

Já o estado 3 também é influenciado por todas as variáveis, com exceção apenas do prêmio de risco soberano. Ou seja, o risco de default dos títulos da dívida brasileira não tem efeito sobre a taxa de câmbio no período americano de elevação dos juros, de outubro de 2004 a abril de 2005, nem no período mais recente, dezembro de 2011 a dezembro de 2012. Dois outros pontos importantes, 1) o diferencial de juros inverte o sentido de efeito sobre o câmbio durante esse estado comparado aos demais estados: quanto maior o diferencial de juros, mais apreciada a taxa de câmbio, 2) o IOF não tem influência na cotação da moeda. Para a explicação do estado 3 a variável mais relevante foi índice internacional de commodities. 
Quanto às hipóteses, muito já foi compreendido a partir da descrição desenvolvida até aqui. Sumariamente tem-se então:

Hipótese 1: As políticas de intervenção no mercado de moeda são eficazes na gestão da dinâmica do câmbio.

As intervenções do BCB não foram significativas na explicação das variações ou nível da taxa de câmbio em nenhum dos subperíodos identificados nos estados markovianos, e, portanto, também não explicaram as mudanças de regime. Ainda, testando-se modelos com um e três estados, essa variável não foi significativa. De fato, as estimativas do modelo tornaramse mais bem ajustadas sem essa variável.

Já quanto às intervenções fiscais por meio do IOF, essa foi significativa apenas em um dos estados, o estado 2, entretanto com resultado de baixa sensibilidade da taxa de câmbio e oposto ao objetivo de política.

Hipótese 2: No pós-crise 2008 houve redução no poder explicativo dos fundamentos de câmbio.

A duração dos estados 2 e 3 no pós-crise de 2008 foi muito próxima e apenas o fundamento prêmio de risco perde significância no fim do período enquanto para variável índice de preços internacional de commodities a sensibilidade da taxa de câmbio aumenta. Portanto, observa-se que a modificação na intensidade como os fundamentos influenciam a cotação da moeda, mas não há uma perda significativa na capacidade de explicação.

Hipótese 3: Há evidências de ocorrência de mudança de regime de câmbio no pós-crise 2008.

Observa-se que do período anterior à crise financeira internacional, ocorre modificação na predominância dos regimes markovianos, desconsiderando o estado 3, atípico. No período anterior à crise foi maior a duração do estado 2 , já no período pós-crise a duração diferiu em apenas dois meses. Isso permite inferir apenas que se mudou de uma tendência de apreciação para tendência de taxa de câmbio desvalorizada no pós-crise. Também se observou que as intervenções das autoridades monetárias e fiscais sobre o mercado de moeda objetivando a gestão da sua dinâmica não tiveram eficácia, o que conjuntamente aos ciclos identificados na taxa de câmbio, contribui para descartar o pensamento das discussões correntes de que o regime de política cambial brasileiro estaria sendo conduzido para um regime de bandas. 


\section{Considerações finais}

O principal objetivo deste trabalho foi buscar evidências de que o regime de política cambial brasileiro teria se alterado no pós-crise econômico-financeira internacional de 2008. As principais motivações para essa hipótese foram o histórico de mudanças de regimes cambial do Brasil e das demais economias emergentes, o que geralmente ocorre em momentos de crises internacionais; a dinâmica recente do real cuja variação tem se descolado da dinâmica das demais commodity currencies; e as inovações em políticas das autoridades monetárias e fiscais visando à gestão da cotação da moeda.

A aplicação do modelo de mudança de regime na série da taxa de câmbio permitiu compreender a dinâmica no período recente e como os fundamentos e intervenção perdem e ganham influência na determinação na cotação ao longo dos ciclos cambiais. Por exemplo, durante o período de crise, os fundamentos conhecidos não foram suficientes para explicar o aumento de volatilidade, a partir do que se compreende que políticas que intervenham nessas variáveis são insuficientes para garantir a estabilidade da taxa de câmbio. Disso decorre que ações de politica econômica que visem a atuar sobre o mercado de moeda devem-se atentar à identificação dos fatores conjunturais que pressionam a cotação da moeda a cada ciclo.

Quanto aos resultados, não foram encontradas evidências representativas de modificação na dinâmica da taxa de câmbio no pós-crise que conduzam a interpretação de alteração no regime de política cambial adotado pelo Brasil; tampouco foi encontrado que as intervenções das autoridades monetárias obtiveram eficácia em gerir a variação ou nível da taxa de câmbio. Entretanto, a julgar pelos objetivos das políticas de intervenção e a frequência com que ocorreram, poder-se-ia dizer que o Brasil está sob o regime de bandas cambiais. De outro modo, sob a ótica dos resultados dessas intervenções, esses foram ineficazes, de forma que prevalece a flutuação com administração ineficaz. É possível que ausência de uma definição de objetivos estruturados de política cambial pelas autoridades brasileiras esteja mitigando os resultados das políticas. As ações de intervenção adotadas no pós-crise tiveram todas um caráter de curto prazo e se sucederam em algo como um método de tentativo e erro, sem um alvo de longo prazo que orientasse o comportamento dos agentes.

Em outro ponto, foi encontrada certa limitação na utilização das variáveis de intervenção do BCB que não se mostraram significativas na explicação da taxa de câmbio sob nenhuma das perspectivas adotadas. Por essa dificuldade, recomenda-se que pesquisas futuras aprimorem na construção de um índice de intervenção que considere o peso de cada instrumento de política. 
Outra abordagem possível é a adaptação do modelo teórico a fim de construí-lo para dados diários, o que pode contribuir para obtenção de resultados mais apurados.

Como perspectiva de pesquisa futura, recomenta-se também a investigação das razões para o descolamento da cotação da moeda nacional das demais commodity currencies ou qual a influência da variação de preços de commodities sobre a cotação do real.

\section{Referências}

ABNT Associação Brasileira de Normas Técnicas. NBR 14.724, de 17.03.2011.Informação e documentação, trabalhos acadêmicos, apresentação. Válida a partir de 17.04.2011. Rio de Janeiro, 2011.

ALMEIDA, M.; FONTES, R. M. O.; ARBEX, M. A. Restropectiva dos regimes cambiais brasileiros com ênfase em bandas de câmbio. Ensaios fundação de Economia e estatística, Porto Alegre, v. 21, n. 1, p. 7-43, 2000.

BANCO CENTRAL DO BRASIL. Boletim de análise do mercado de câmbio. 1999. Disponível em: < http://www.bcb.gov.br >. Acesso em: 3 jul. 2012.

BANCO CENTRAL DO BRASIL - BCB. Comunicado n. 6.565, de 18 de janeiro de 1999. Dispõe sobre o regime cambial. Disponível em: < http://www.bcb.gov.br >. Acesso em: 3 jul. 2012.

Regimes de metas para inflação no Brasil, Brasília, 2013. (Série perguntas mais frequentes). Disponível em: < http://www.bcb.gov.br >. Acesso em: 3 jul. 2013a.

Sistema de informações do Banco Central, Brasília, 2013. Disponível em: <http://www.bcb.gov.br $>$. Acesso em: 3 jul. 2013 b.

BERGMAN, U. M.; HANSSON, J. Real exchange rates and switching regimes. Journal of International Money and Finance, Philadelphia, v. 24, n. 1, p. 121-138, 2005. crossref http://dx.doi.org/10.1016/j.jimonfin.2004.10.002

BOGDANSKI, J.; TOMBINI, A. A.; WERLANG, S. R. Implementing inflation targeting in Brazil. Working Paper Series, Brasília, v. 1, n. 1, p. 1-29, 2000.

BOLLEN, N. P.; GRAY, S. F.; WHALEY, R. E. Regime switching in foreign exchange rates: Evidence from currency option prices. Journal of Econometrics, Philadelphia, v. 94, n. 1, p. 239-276, 2000. crossrefhttp://dx.doi.org/10.1016/S0304-4076(99)00022-6

CALVO, G. A.; REINHART, C. M. Fear of floating. Quarterly Journal of Economics, Oxford, v. 117, n. 2, p. 379-408, 2002. crossref http://dx.doi.org/10.1162/003355302753650274

CHEN, Y.-C.; ROGOFF, K. Commodity currencies. Journal of International Economics, Philadelphia, v. 60, n. 1, p. 133-160, 2003. crossrefhttp://dx.doi.org/10.1016/S00221996(02)00072-7 
CLEMENTS, K. W.; FRY, R. Commodity currencies and currency commodities. Resources Policy, Philadelphia, v. 33, n. 2, p. 55-73, 2008. crossref http://dx.doi.org/10.1016/j.resourpol.2007.10.004

CÓDIGO TRIBUTÁRIO NACIONAL, 25 de outubro de 1966. Dispõe sobre o Sistema Tributário nacional e institui normas gerais aplicáveis à União, Estados e Municípios. Disponível em: < http://www.planalto.gov.br >. Acesso em: 10 jan. 2013.

DA ROSA BORGES, R.; JÚNIOR, J. L. R. Intervenções do Banco Central do Brasil (BCB) e previsibilidade da taxa de câmbio: evidências a partir da utilização de regras de negociação baseadas em análise técnica. Pesquisa e Planejamento Econômico, Brasília, v. 40, n. 3, p. 349-366, 2010.

DORNBUSCH, R.; FISCHER, S. Stopping hyperinflations past and present. Review of World Economics (Weltwirtschaftliches Archiv), Hindenburgufer, v. 122, n. 1, p. 1-47, 1986.

ENGEL, C. Can the Markov Switching Model forecast exchange rates? Journal of International Economics, Philadelphia, v. 36, n. 1, p. 151-165, 1994. crossref http://dx.doi.org/10.1016/0022-1996(94)90062-0

ENGEL, C.; HAMILTON, J. D. Long Swings in the Dollar: Are They in the Data and Do Markets Know It? The American Economic Review, Pittsburgh, v. 80, n. 4, p. 689-713, 1990.

FERNANDES, G. Intervenções no mercado de câmbio brasileiro: investigação empírica dos determinantes. São Paulo: ITAÚ BBA, 2013, p. 1-17. (Texto para discussão n.9)

FIESS, N.; SHANKAR, R. Determinants of exchange rate regime switching. Journal of International Money and Finance, Philadelphia, v. 28, n. 1, p. 68-98, 2009. crossref http://dx.doi.org/10.1016/j.jimonfin.2007.08.002

FRENKEL, R.; RAPETTI, M. A concise history of exchange rate regimes in Latin America. Center for Economic and Policy Research, Washington, 2010.

FRÖMMEL, M.; MACDONALD, R.; MENKHOFF, L. Markov switching regimes in a monetary exchange rate model. Economic Modelling, Philadelphia, v. 22, n. 3, p. 485-502, 2005. crossrefhttp://dx.doi.org/10.1016/j.econmod.2004.07.001

FUNDAP. Os fluxos de capitais para a Economia brasileira em 2011. Boletim de Economia Conjuntura Econômica em foco, São Paulo, v. 1, n. 10, p. 1-20, 2011.

HAMILTON, J. D. A new approach to the economic analysis of nonstationary time series and the business cycle. Econometrica: Journal of the Econometric Society, Madrid, p. 357-384, 1989.

Analysis of time series subject to changes in regime. Journal of econometrics, Madrid, v. 45, n. 1, p. 39-70, 1990.

Specification testing in Markov-switching time-series models. Journal of Econometrics, Madrid, v. 70, n. 1, p. 127-157, 1996.

HOLLAND, M. Entrevista concedida ao jornal Valor Econômico em 17 de dezembro de 2012. Disponível em: < 
http://www1.fazenda.gov.br/resenhaeletronica/MostraMateria.asp?cod=863481 >. Acesso em: 10 jan. 2013.

KOHLSCHEEN, E. Emerging floaters: pass-throughs and (some) new commodity currencies. Journal of International Money and Finance, Philadelphia, v. 29, n. 8, p. 1580-1595, 2010. crossrefhttp://dx.doi.org/10.1016/j.jimonfin.2010.05.013

LEE, H.-Y.; CHEN, S.-L. Why use Markov-switching models in exchange rate prediction? Economic Modelling, Philadelphia, v. 23, n. 4, p. 662-668, 2006. crossref http://dx.doi.org/10.1016/j.econmod.2006.03.007

MUINHOS, M. K.; ALVES, S. A. L.; RIELLA, G. Modelo estrutural com setor externo: endogenização do prêmio de risco e do câmbio. Brasília: BANCO CENTRAL DO BRASIL, 2002, v. 1. (Working Paper)

MUNHOZ, V. D. C. V. Vulnerabilidade externa e controle de capitais no Brasil: uma análise das inter-relações entre câmbio, fluxos de capitais, IOF, juros e risco-país. Nova Economia, Belo Horizonte, v. 23, n. 2, p. 371-402, 2013. crossrefhttp://dx.doi.org/10.1590/S010363512013000200005

NIKOLSKO-RZHEVSKYY, A.; PRODAN, R. Markov switching and exchange rate predictability. International Journal of Forecasting, Philadelphia, v. 28, n. 2, p. 353-365, 2012. crossrefhttp://dx.doi.org/10.1016/j.ijforecast.2011.04.007

OLIVEIRA, F. N. D.; PLAGA, A. Eficácia das intervenções do Banco Central do Brasil sobre a volatilidade condicional da taxa de câmbio nominal. Revista brasileira de Economia, São Paulo, v. 65, n. 1, p. 71-92, 2011.

ROSSI, P. Política Cambial no Brasil: um Esquema Analítico. In: FORUM DE ECONOMIA DA FUNDAÇÃO GETÚlIO VARGAS, 10., 2013, São Paulo, Palestra.

SANIDAS, E. Four harmonic cycles explain and predict commodity currencies' wide long term fluctuations. Technological Forecasting and Social Change, 2013.

SARNO, L.; VALENTE, G.; WOHAR, M. E. Monetary fundamentals and exchange rate dynamics under different nominal regimes. Economic Inquiry, Eugene, v. 42, n. 2, p. 179193, 2004. crossrefhttp://dx.doi.org/10.1093/ei/cbh053

SILVA, G. J. C. D.; RESENDE, M. F. D. C. Eficácia dos controles de capitais no Brasil: uma abordagem teórica e empírica alternativa. Estudos Econômicos, São Paulo, v. 40, n. 3, p. 617-649, 2010. crossrefhttp://dx.doi.org/10.1590/s0101-41612010000300005

SILVEIRA, M. D. Intervenção da autoridade monetária no mercado de câmbio em regime de flutuação administrada. Brasília: BANCO CENTRAL DO BRASIL, 2003. (Nota técnica do Banco Central do Brasil, n. 34)

SCHWARTSMAN, A.; PINHEIRO, T. A taxa de câmbio no jardim dos caminhos que se bifurcam. Revista Brasileira de Comércio Exterior, São Paulo, v. 105, p. 16-23, 2010.

WALID, C.; CHAKER, A.; MASOOD, O.; FRY, J. Stock market volatility and exchange rates in emerging countries: A Markov-state switching approach. Emerging Markets Review, Philadelphia, v.12, n. 3, p. 272-292, 2011. crossref http://dx.doi.org/10.1016/j.ememar.2011.04.003 
WILFLING, B. Volatility regime-switching in European exchange rates prior to monetary unification. Journal of International Money and Finance, Philadelphia, v. 28, n. 2, p. 240270, 2009. crossrefhttp://dx.doi.org/10.1016/j.jimonfin.2008.08.005

YUAN, C. Forecasting exchange rates: The multi-state Markov-switching model with smoothing. International Review of Economics \& Finance, Philadelphia, v. 20, n. 2, p. 342362, 2011. crossrefhttp://dx.doi.org/10.1016/j.iref.2010.09.002

Recebido em 18.02.14

Aprovado em 05.02.15 